\title{
Arquitetura e mecanismos deposicionais em sistemas aluviais holocênicos de clima árido no oeste argentino e comparação com depósitos neocretáceos brasileiros
}

\author{
Alessandro Batezelli' \& Giorgio Basilici ${ }^{2}$
}

\begin{abstract}
Resumo A Pré-Cordilheira, na região noroeste da Argentina, é caracterizada por feições geomorfológicas originadas do soerguimento miocênico que deu origem a Cordilheira dos Andes. O clima árido e o regime tectônico compressivo propiciaram a geração de inúmeras bacias sedimentares onde se desenvolveram depósitos aluviais e de lagoas efêmeras (playa-lakes). Por se tratar de ambientes ativos e recortados por drenagens fluviais atuais, essas bacias constituem importantes sítios de observação direta para análises das fácies e arquiteturas deposicionais aluviais, pela grande quantidade e qualidade de afloramentos. A descrição de alguns desses depósitos no Vale do Rio Jáchal (próximo à cidade de San José de Jáchal) e na planície aluvial do Deserto de Pie de Palo nas imediações de San Juan, permitiu identificar os principais mecanismos deposicionais atuantes nestes ambientes. Para isso foram selecionados afloramentos-chave dispostos em seções longitudinais aos sistemas de leques aluviais, onde se constatam interdigitações destes com depósitos de lagoas efêmeras (playa-lakes) e campos de dunas eólicas. Foram caracterizadas as geometrias internas e externas dos corpos sedimentares a partir da análise de superfícies hierárquicas e de macroformas que permitiram interpretar os processos sedimentares atuantes e a dinâmica deposicional. A variação faciológica encontrada entre os depósitos proximais e distais registra a evolução de fluxos de detritos não-coesivos (confinados ou não), para fluxos turbulentos e laminares, como resultado da diminuição de energia das correntes de enxurradas efêmeras de períodos de tempestade. Em virtude da baixa pluviosidade, da ordem de $70 \mathrm{~mm} / \mathrm{ano}$, a taxa de sedimentação também é muito baixa, atestada principalmente pelo desenvolvimento de vegetação arbustiva e formação de solos recentes. Embora a análise tenha sido feita em áreas restritas e com história sedimentar muito recente (Pleistoceno tardio ao Holoceno), a distribuição das fácies e os mecanismos deposicionais, condicionada pela posição geomorfológica no sistema de leques aluviais e as características sedimentológicas impostas pelo clima árido, servem como elemento de comparação com depósitos neocretáceos brasileiros, sobretudo os da Bacia Bauru, que apresentam características sedimentológicas e arquitetônicas semelhantes.
\end{abstract}

Palavras-Chave: Leques aluviais, Planície Arenosa, Campo de Dunas, mecanismos deposicionais, clima árido.

\begin{abstract}
Architecture and depositional mechanisms inthe holocene arid climate alluvial systems in the western argentine and comparison with brazilian neocretaceous deposits. The Pre-Cordillera in the northwest of Argentine is characterized by geomorphological features formed during Miocene Andes Cordillera uplifting. The arid weather and compressive tectonic regime propitiated the origin of countless sedimentary basins filled by alluvial fans and playa-lakes deposits. Because of the outcrops abundance and their qualities these basins are important sites for direct observation of depositional alluvial architectures and facies analyses. The description of some deposits in the Rio Jáchal valley (neighborhood of San Jose de Jáchal), and Pie de Palo desert alluvial plain in San Juan, allowed the recognition of main depositional mechanisms in these environments. The analyses were based in the longitudinal cross sections that show intertonguing of the alluvial fans, playa-lakes and eolian deposits. It was characterized the internal and external geometries of the bodies by hierarchical surfaces and macroforms analyses to make the interpretation of the sedimentary process and the depositional dynamics. The facies variation from proximal to distal deposits recorded the evolution of confined or unconfined non-cohesive debris flow to turbulent and laminar flows, resulting by the transport stream energy decrease of ephemeral torrential currents associated with storm periods. Due to the annual low pluviosity $(70 \mathrm{~mm} / \mathrm{y})$, the sedimentation rate is very low, mainly suggested by the vegetation and soil developed. Although this study has been made in a restrict area with a very recent sedimentary history initiated only in the Late Pleistocene to Holocene, the facies distribution and the depositional mechanisms conditioned by geomorphologic positions in the alluvial fan systems and the sedimentologic characteristics conditioned by the arid climate allow to compare these deposits with the Brazilian neocretaceous, in the Bauru Basin, that shows similar sedimentologic and architecture characteristics.
\end{abstract}

Keywords: Alluvial fans, sand flat, dunes field, Playa Lake, depositional mechanisms, arid climate.

1 - Programa de Pós-Graduação, Instituto de Geociências, Universidade Estadual de Campinas (SP), Brasil. E-mail: alessandro.batezelli@ gmail.com

2 - Departamento Geologia e Recursos Naturais, Instituto de Geociências, Universidade Estadual de Campinas, Campinas (SP), Brasil 


\section{INTRODUÇÃO}

Generalidades A análise de fácies e arquitetura de sistemas aluviais de clima árido tem sido alvo um grande número de pesquisas em todo mundo, seja para definição e caracterização de reservatórios de hidrocarbonetos (Miall, 1985; 1988a; 1988b; 1996), seja para reconstrução paleoambiental e modelos de evolução de seqüências continentais a partir da identificação de elementos arquitetônicos e superfícies limítrofes (Hirst, 1991; Miall \& Tyler, 1991; McCarthy \& Plint, 1998; Martinsen et al., 1999; McCarthy et al., 1999; Jones et al., 2001; Miall \& Jones, 2003; Komatsubara, 2004). O presente trabalho tem como objetivo apresentar um estudo dos mecanismos deposicionais a partir da observação direta de sistemas de leques holocênicos e atuais da Pré-Cordilheira Andina, nas proximidades dos municípios de San Jose de Jáchal e San Juan, no oeste argentino (Fig. 1).
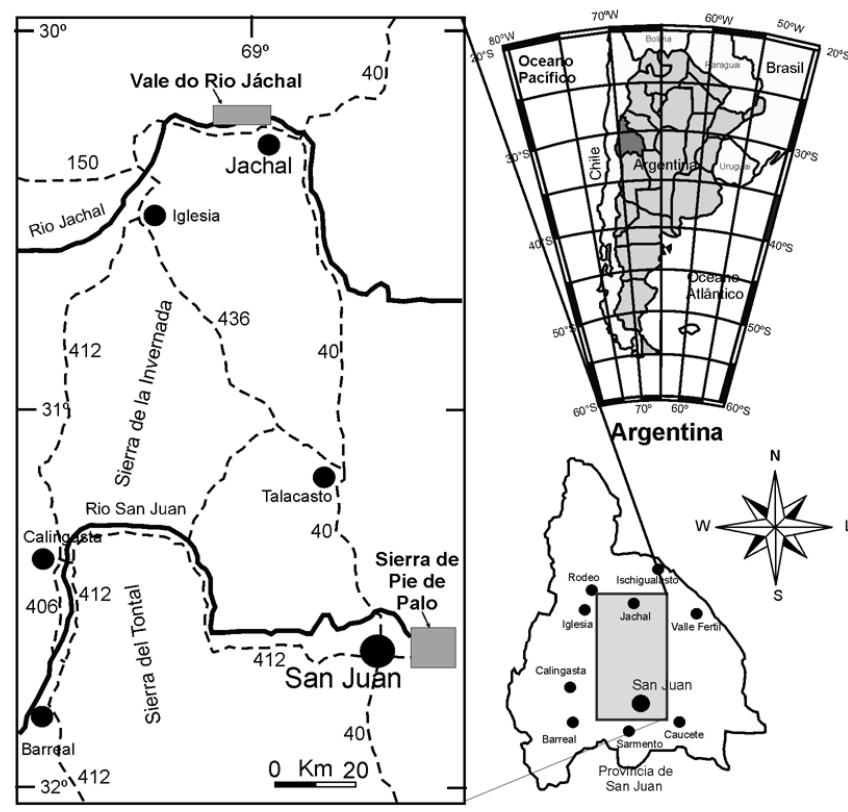

Figura 1 - Mapa de localização da Pré-Cordilheira Argentina e posição geográfica do sistema de leques e playa lake do Vale do Rio Jáchal e do sistema de leques aluviais do Deserto de Pie de Palo (Cutolo, 2005)

Pré-Cordilheira Argentina e seus depósitos aluviais A Pré-Cordilheira Argentina é uma entidade geotectônica de idade miocênica, com forma alongada na direção Norte-Sul e situada entre a Cordilheira Frontal Andina, a oeste, e a Sierra Pampeana, a leste (Fig. 1). É constituída por uma faixa de dobramentos e cavalgamentos com vergência para leste (thrustfold chain), que abriga uma sucessão sedimentar formada por rochas cujas idades variam do Cambriano Inferior até o Neógeno. Atualmente, entre os sistemas de dobras de empurrão se formam pequenas bacias de sedimentação continental (bacias de thrust-sheet top ou bacias de piggy-back), influenciadas por dois fatores básicos que condicionaram a geomorfologia da área: o clima árido e a tectônica.

Nestas condições de grandes desníveis topográficos, aliados à ausência de vegetação ou presença de vegetação rarefeita, são gerados depósitos sedimentares clásticos, textural e mineralogicamente imaturos que preenchem as bacias de thrust-sheet top, freqüentemente fechadas e caracterizadas por drenagem endorreica. A combinação destes fatores produz um cenário fisiográfico constituído por leques aluviais que margeiam uma bacia lacustre efêmera no centro, constituindo assim, um sistema de leques e playa-lake.

O Sistema de leques aluviais e playa-lake do Vale do Rio Jáchal é um sistema deposicional inativo e em processo de erosão, cujo desenvolvimento provavelmente foi interrompido no Holoceno (Colombo et al. 2004) e que conserva perfeitamente todas as estruturas morfo-deposicionais e a posição geográfica (Figs. 1 e 2).

Localizada a leste da cidade de San Juan, na porção NW da Argentina, a região de Pie de Palo (denominação da serra homônima), possui uma área aproximada de $6500 \mathrm{~km}^{2}$, abrangendo duas feições geomorfológicas marcantes: a Serra de Pie de Palo e o Deserto de Pie de Palo. Ao norte e leste é limitada pelo Vale do Rio Bermejo e a oeste e sul pelo Vale do Rio San Juan (Figs. 1 e 3).

No sopé da Serra de Pie de Palo desenvolvemse leques aluviais coalescentes dominados por fluxos gravitacionais que se espraiam para todas as direções. Os leques que se desenvolvem para norte, leste e oeste são retrabalhados pelos rios Bermejo e San Juan, respectivamente. Já o sistema de leques que se forma na porção sul da Serra de Pie de Palo é retrabalhado por drenagens efêmeras e por um sistema de dunas eólicas limitados a sul pelo rio San Juan (Deserto de Pie de Palo).

A área de estudo situa-se a sul da Serra de Pie de Palo, na planície aluvial entre o sopé da Serra de Pie de Palo e o vale do rio San Juan. A principal via de acesso é a rodovia Caucete - Vallecito, que secciona transversalmente os leques aluviais. Além dessa, encontram-se muitas estradas não pavimentadas que ligam a rodovia ao interior da planície e ao topo da Serra de Pie de Palo.

MÉTODO DE TRABALHO E AQUISIÇÃo DE DADOS DE CAMPO Os dados de campo foram coletados duas etapas de trabalho no noroeste da Argentina, na região de San Jose de Jáchal e no Deserto de Pie de Palo, respectivamente. (Figs. 1, 2 e 3).

Foram feitas descrições de afloramentos contemplando características texturais (composição, granulometria, esfericidade dos grãos, seleção, etc.), estruturas sedimentares e níveis de solos presentes, permitindo, assim, reconhecer feições que indicam, além dos processos e estilos fluviais e eólicos, períodos com maior e menor taxa de sedimentação.

Além das fácies, foram estudados os elementos 


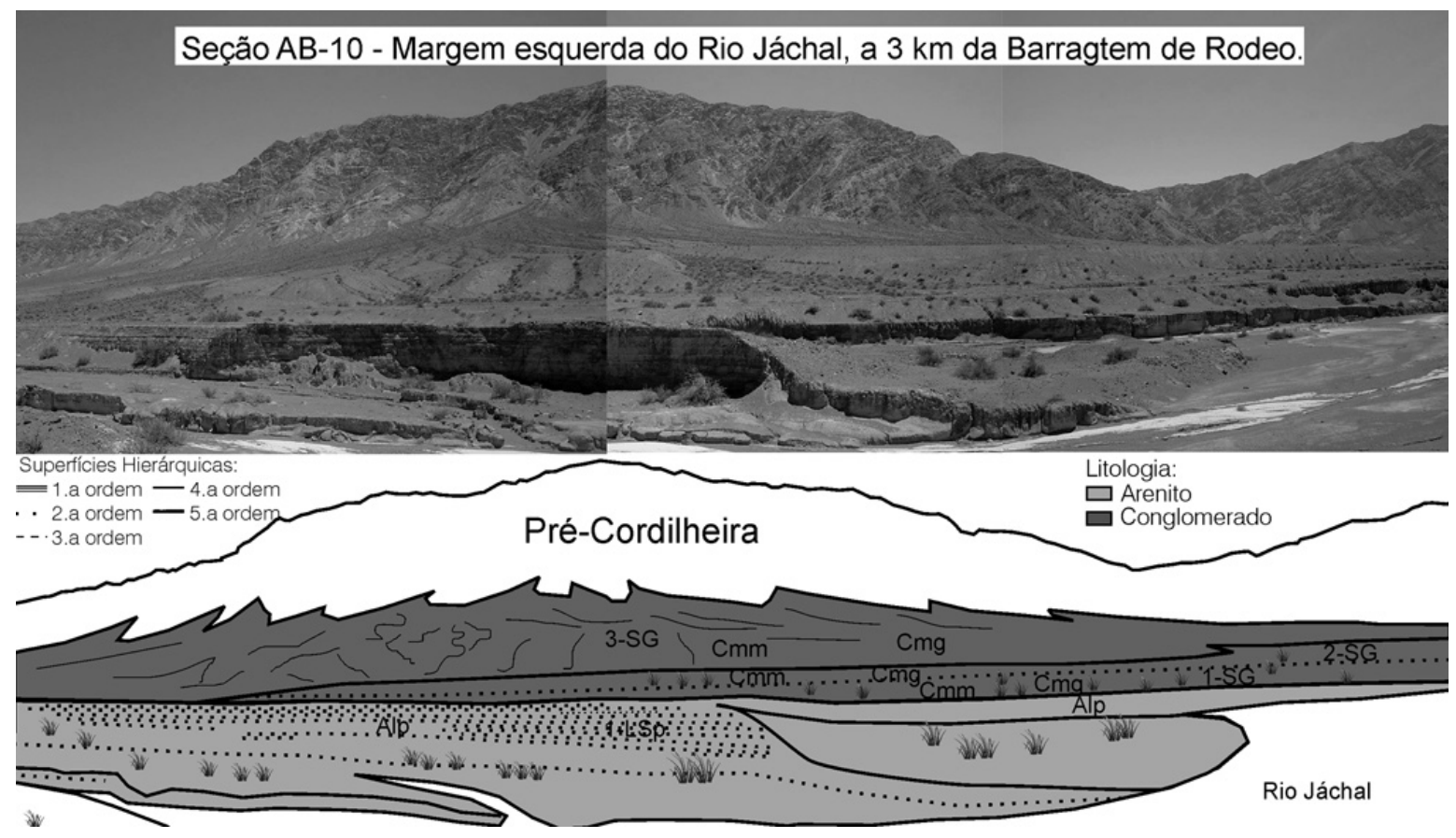

Figura 2 - Vista panorâmica do sistema de leques aluviais e depósitos de playa lake do Vale do Rio Jáchal.

arquitetônicos (Miall, 1985 e 1996). As fácies descritas seguem o padrão do código proposto por Miall (1985) (Quadro 1).

Utilizada por muitos autores para determinação de estilos fluviais (e.g. Miall 1988a, 1988b, 1994 e 1996; Miall \& Turner-Peterson, 1989; Miall \& Tyler, 1991; Smith, 1990; Cowan, 1991; Decelles et al, 1991; Bridge, 1993; Ferreira Jr. \& Guerra, 1995; Ferreira Jr., 1996; Lima \& Villas-Boas, 2000; Jones et al., 2001; Batezelli, 2003; Batezelli et al. 2007), a aplicação desse método deveu-se, sobretudo, aos afloramentos com grande extensão lateral que ocorrem na área estudo, permitindo assim a confecção de painéis fotográficos para análise do traçado das superfícies limítrofes dos corpos sedimentares, identificação de superfícies hierárquicas e de macroformas. Em alguns pontos foram escavadas trincheiras rasas que permitiram analisar em detalhe as estruturas e texturas sedimentares de corpos arenosos.

\section{FÁCIES E ARQUITETURAS DEPOSICIONAIS}

Os depósitos do Vale do Rio Jáchal Os depósitos holocênicos e atuais da Pré-Cordilheira Argentina, no Vale do Rio Jáchal, foram estudados nas proximidades da Barragem de Rodeo, entre a cidade homônima e San Jose de Jáchal, conforme mencionado anteriormente (Figs. 1 e 2). Foram reconhecidas e descritas detalhadamente cinco seções estratigráficas identificando os elementos arquitetônicos. No presente trabalho, serão apresentadas somente as mais representativas.

SEÇÃO AB-06 (COORDENADAS GEOGRÁFICAS: $30^{\circ} 12^{\prime} 48^{\prime \prime} S X 69^{\circ} 01$ ' 30” $W$ ) Esta seção localizase no vale do Rio Jáchal, próximo à barragem de Ro- deo, na região conhecida como Cuesta Del Viento (Fig. 4), entre os municípios de San Jose de Jáchal e Rodeo (margem direita do rio). Trata-se de uma extensa seção entalhada pela drenagem atual e apresenta altura média de 20 metros (até 50 metros em alguns pontos), por 3,5 $\mathrm{km}$ de extensão. Na sua base ocorrem areias muito finas a finas, com estratificação plano-paralela (fácies Alp) e muitas marcas de raízes. Rumo ao topo ocorrem cascalhos sustentados pela matriz e por clastos (fácies $\mathrm{Cmm}$ e Cmg), em ciclos granodecrescentes ascendentes (Fig. 4).

Os ciclos granodecrescentes ascendentes possuem espessura variável entre 30 centímetros e 1 metro. Possuem base abrupta e topo gradacional e as fácies variam entre cascalho maciço sustentado por matriz e areia laminando (fácies $\mathrm{Cmm}$ e Alp). Em alguns locais encontra-se a fácies Cmg em contato abrupto com a fácies Alp.

As superfícies que separam as fácies Alp e Cmg/ Cmm são de 3.a ordem, côncavas para cima e irregulares. As fácies cascalhentas estão limitadas por elementos $\mathrm{CH}$ (canais menores), com geometria lenticular, enquanto que as fácies Alp apresentam formas tabulares, bastante extensas, interpretadas como depósitos formados a partir de fluxos distais em lençol (Fig. 4).

Superfícies de 2.a ordem separam os estratos cascalhentos com granodecrescência ascendente. Nos estratos arenosos (fácies Alp) não se observam superfícies de 2.a ordem. As superfícies de 1.a ordem são mais nítidas principalmente na fácies Alp, representadas pelas laminações plano-paralelas. Superfícies de maior ordem (6.a ordem) podem ser identificadas no contorno dos leques em planta (Fig. 4A).

SEÇÃO AB-09 (COORDENADAS GEOGRÁFICAS: 

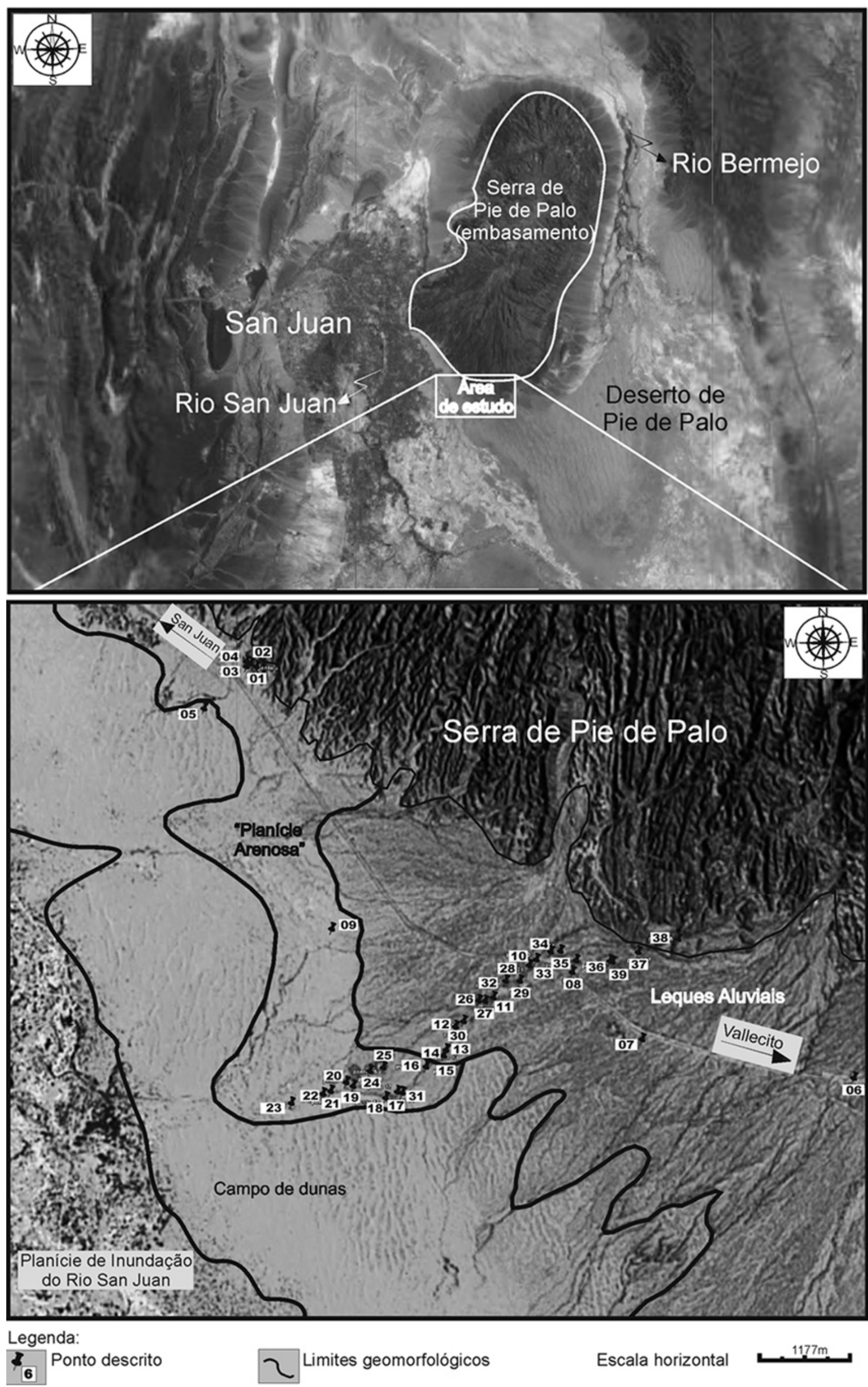

Figura 3 - Imagem de satélite mostrando a localização da área de estudos. 
Tabela 1 - Código de fácies utilizado no estudo dos depósitos de San Jose de Jáchal e da Serra de Pie de Palo (Oeste Argentino - Adaptados de Miall, 1985).

\begin{tabular}{l|l}
\hline Litofácies & \multicolumn{1}{c}{ Características texturais e estruturas sedimentares } \\
\hline $\mathbf{C m m}$ & Conglomerado maciço, sustentado por matriz. \\
\hline $\mathbf{C m g}$ & Conglomerado maciço, sustentado por clastos. \\
\hline $\mathbf{C p}$ & Conglomerado com seixos imbricados, sustentado por clastos. \\
\hline $\mathbf{A m}$ & Arenito maciço, com ou sem clastos dispersos. \\
\hline $\mathbf{A e a}$ & Arenito com estratificação cruzada acanalada (pequeno Aeap, médio Aeam e grande porte Aeag). \\
\hline $\mathbf{A e a b}$ & Arenito com estratificação cruzada acanalada de baixo ângulo. \\
\hline $\mathbf{A e t}$ & Arenito com estratificação cruzada tabular (pequeno, médio e grande porte). \\
\hline $\mathbf{A e h}$ & Arenito com estratificação sub-horizontal. \\
\hline $\mathbf{A l p}$ & Arenito com laminação plano-paralela. \\
\hline $\mathbf{A o}$ & Arenito com marcas onduladas. \\
\hline $\mathbf{F m}$ & Argilito maciço. \\
\hline $\mathbf{F m a}$ & Lamito maciço com lentes de arenito. \\
\hline
\end{tabular}

$31^{\circ} 20^{\prime} 50^{\prime \prime} \mathrm{S} X 69^{\circ} 10^{\prime} 01^{\prime \prime} \mathrm{W}$ ) Situada na margem esquerda do Rio Jáchal, $1 \mathrm{~km}$ à jusante da Barragem de Rodeo, essa seção apresenta 500 metros de extensão e 10 metros de altura (em média) e mostra na sua base areias esbranquiçados, finas a médias, com laminações plano-paralelas (fácies Alp) em contato com cascalhos maciços sustentados por matriz e por clastos (fácies Cmm e Cmg) (Fig. 5).

Uma superfície de 3.a ordem separa os dois conjuntos de fácies, individualizando dois elementos arquitetônicos distintos: Elemento LS (lençol de areia laminado) na base e Elemento $\mathrm{CH}$ (canais menores) no topo. O elemento LS guarda a mesmas características apresentadas nas seções anteriores e as exposições de boa qualidade não deixam dúvidas para o seu reconhecimento. $\mathrm{O}$ elemento $\mathrm{CH}$ apresenta formas irregulares, frequentemente côncavas para cima, com dezenas de metros de extensão e no máximo 1,20 metro de espessura. Observa-se que, rumo ao topo, existe um aumento na quantidade de elementos $\mathrm{CH}$ menores. A fácies Alp apresenta marcas de raízes e em alguns pontos observam-se também suaves ondulações (Fig. 6).

Os depósitos do Deserto de Pie de Palo As fácies e as arquiteturas deposicionais do sistema de leques da região de Pie de Palo aqui apresentadas são reconhecidas em afloramentos descritos ao longo de um perfil longitudinal, que permitiu correlacionar os mecanismos deposicionais com as zonas geomorfológicas (Fig. 3).

DEPÓSITOS PROXIMAIS - DOMINADOS POR FLUXOS DE DETRITOS NÃO-COESIVOS Ao sul da Serra de Pie de Palo, especificamente no sopé da elevação, desenvolvem-se depósitos grossos, caracterizados por clastos angulosos, com dimensões variadas, desde centímetros até metros, com formas achatadas, que se distri- buem de forma irregular (franja) ao longo de uma faixa que vai desde a serra até algumas centenas de metros em direção a planície aluvial (Fig. 3).

Esses depósitos, muitas vezes confinados pela topografia, se concentram em vales estreitos nas reentrâncias da Serra de Pie de Palo. Possuem duas geometrias diferenciadas: a primeira, sob a forma de grandes barras longitudinais, tabulares ou lenticulares, com convexidade para cima, espessuras métricas, composta por clastos angulosos com dimensões variando de calhaus a matacões, predominando calhaus, que entulham os vales estreitos.

Os clastos, de composição essencialmente gnáissica (biotita gnaisse), estão frequentemente imbricados no sentido norte e formam depósitos com quantidade variável de matriz (Elemento GB). Em alguns locais observam-se a presença de clastos menores (seixos) que preenchem os espaços entre os clastos maiores, originando depósitos de peneiramento (sieve deposits de Hooke, 1967).

Associados a esses depósitos ocorrem subordinadamente camadas irregulares, pouco espessas e isoladas de diamictos constituídos por matacões e calhaus imersos em matriz fina (elemento SG).

O segundo tipo de corpo sedimentar encontrado nessa porção possui geometria lenticular em seção transversal formado em canais estreitos, retilíneos, que bordejam barras cascalhentas. Esses apresentam matriz arenosa grossa e ciclos granodecrescentes ascendentes. A distribuição desses elementos pode ser visualizada no esquema da figura 7 .

Além desses, ocorrem subordinadamente depósitos arenosos com granulometria média a fina, pouco espessos, por vezes retrabalhados por vento. Em alguns pontos é possível observar superfícies de deflação eólica onde se concentram clastos com dimensões entre 


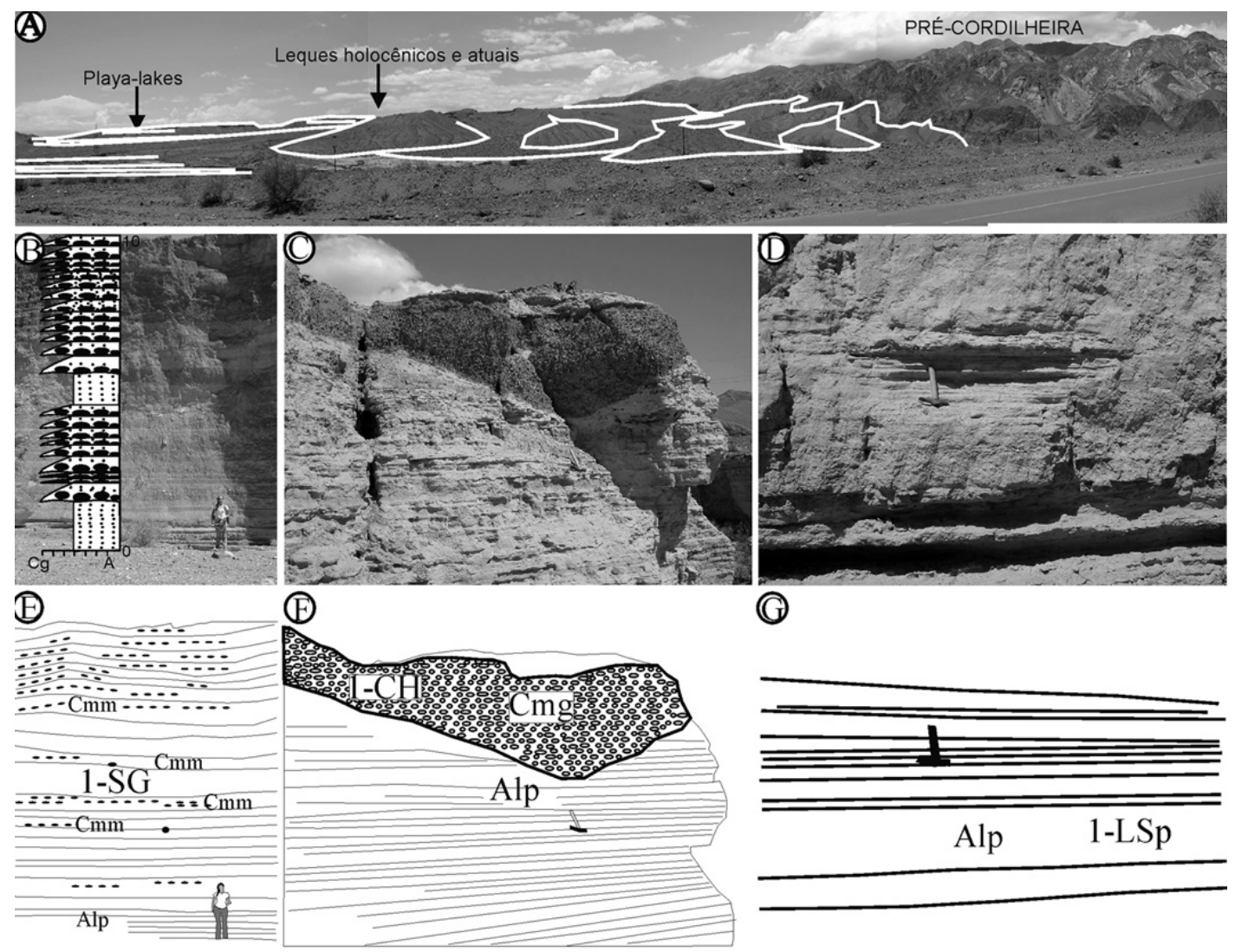

Figura 4 - Características faciológicas da seção AB-06. A - Depósitos de leques e de lençol no vale do Rio Jáchal na Pré-Cordilheira Argentina. B - Afloramento mostrando estratos tabulares de cascalhos com granodecrescência ascendente (fácies Cmm). C-Detalhe da fácies Alp e Cmg mostrando a geometria em canal. D - Areia muito fina a fina com laminações plano-paralelas (fácies Alp). E, F e $G$-Principais superfícies e elementos arquitetônicos.

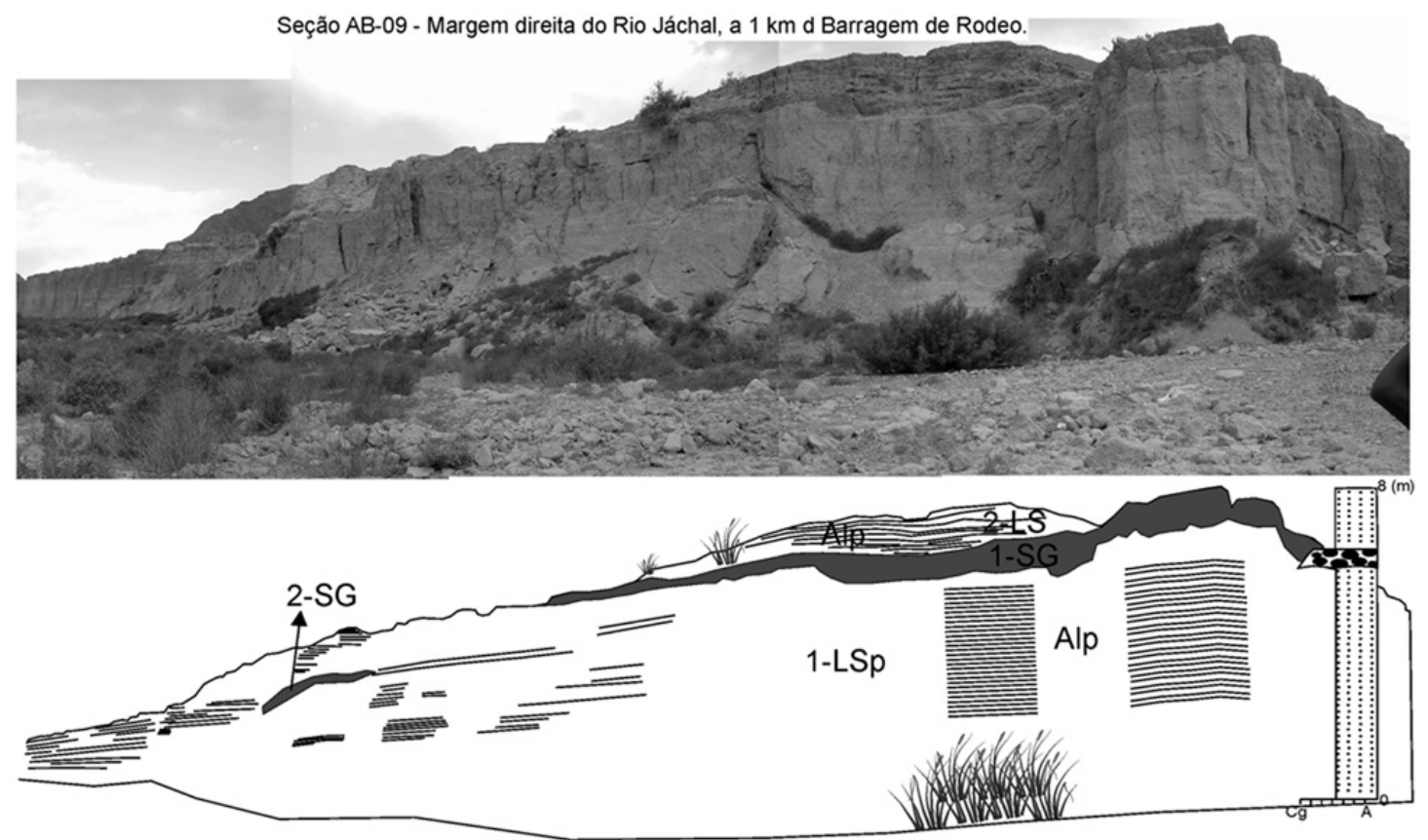

Figura 5 - Fácies e elementos arquitetônicos da seção AB-09. 

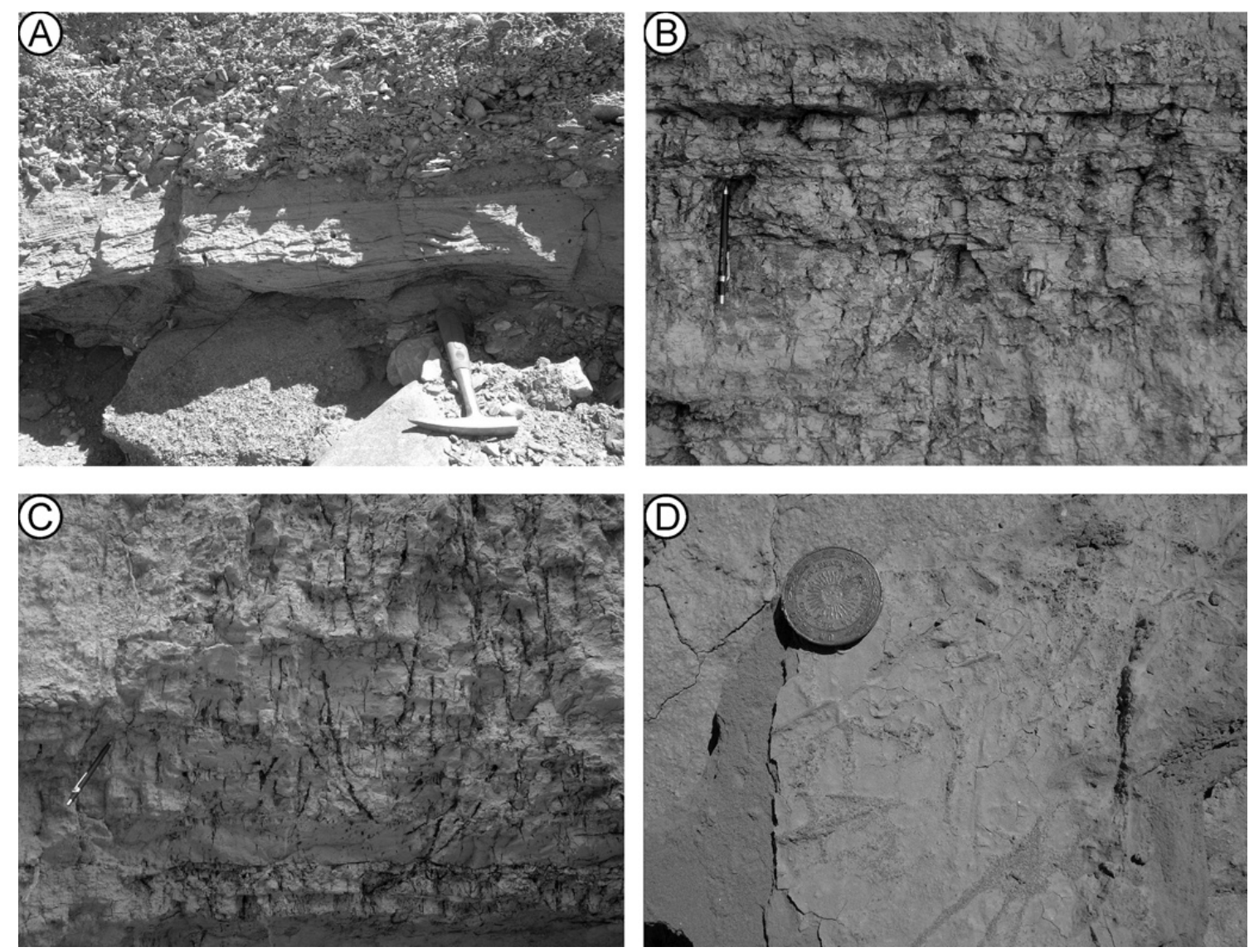

Figura 6-Detalhe das fácies encontradas na seção AB-10. A-Contato irregular entre as areias com laminações onduladas, plano-paralelas e os cascalhos maciços sustentados por clastos. $B$ - Laminação plano-paralela da fácies Alp. C-Detalhes das marcas de raizes. D-Cristais de gipsita em forma de "cauda de andorinha".

seixos e calhaus (Fig. 8).

Mecanismos deposicionais_As características sedimentológicas de ambos os depósitos são indicativas de sedimentação a partir de fluxos gravitacionais desenvolvidos em regiões cujo gradiente de relevo é superior a 1,5 graus. Esses fluxos, em sua maioria, são confinados em vales do embasamento, estreitos (com pouco mais de 100 metros de largura), retilíneos e se desenvolvem esporadicamente durante períodos de cheias relacionadas a chuvas torrenciais. Tratam-se dos canais alimentadores dos leques aluviais no sopé da Serra de Pie de Palo (Fig. 8).

Inicialmente, desenvolvem-se fluxos de detritos não-coesivos caracterizados pela baixa porcentagem de sedimentos finos (silte e argila) (Lowe, 1979), gerando depósitos de cascalhos sustentados por clastos, com geometria em leques, suavemente côncavas para baixo, com dimensões de centenas de metros. Esses depósitos são retrabalhados por fluxos canalizados que se forma em estágios de menor energia, durante as fases finais dos períodos de tempestades. As características desses depósitos são semelhantes àquelas descritas por Nemec $\&$ Steel (1984).

Os depósitos de diamictos são formados a partir de fluxos de detritos coesivos, cujas características se resumem em alta porcentagem de sedimentos finos (>
$10 \%$ ), comportamento plástico devido à baixa viscosidade e seu movimento interno é mais laminar do que turbulento. Esses depósitos ocorrem subordinados aos depósitos não-coesivos.

Segundo Assine (em preparação), depósitos desse tipo são pouco reconhecidos no registro estratigráfico, pois são freqüentemente considerados produtos de outros processos, tais como inundações torrenciais e efêmeras (streamflood: Steel, 1974; sheetflood: Nemec et al., 1980 e Wasson, 1979).

Delgadas camadas arenosas com laminações cruzadas se formam no topo dos depósitos grossos com a diminuição de energia do fluxo, nos estágios finais das chuvas (waning deposits de Nemec \& Steel, 1984). Nos longos períodos de seca que assolam a região, esses depósitos são retrabalhados por ventos dando origem a pavimentos de clastos (Fig. 8) e desenvolvimento de vegetação que propicia a formação de solos.

\section{DEPÓSITOS PROXIMAIS - DOMINADOS POR FLU-} XOS DE DETRITOS NÃO CONFINADOS E RETRABALHAMENTO FLUVIAL Rumo à planície aluvial, nas porções onde a declividade do relevo ainda é da ordem de 1,5 graus, fora do domínio geomorfológico da Serra de Pie de Palo, os fluxos gravitacionais não encontram barreiras laterais e formam depósitos não 


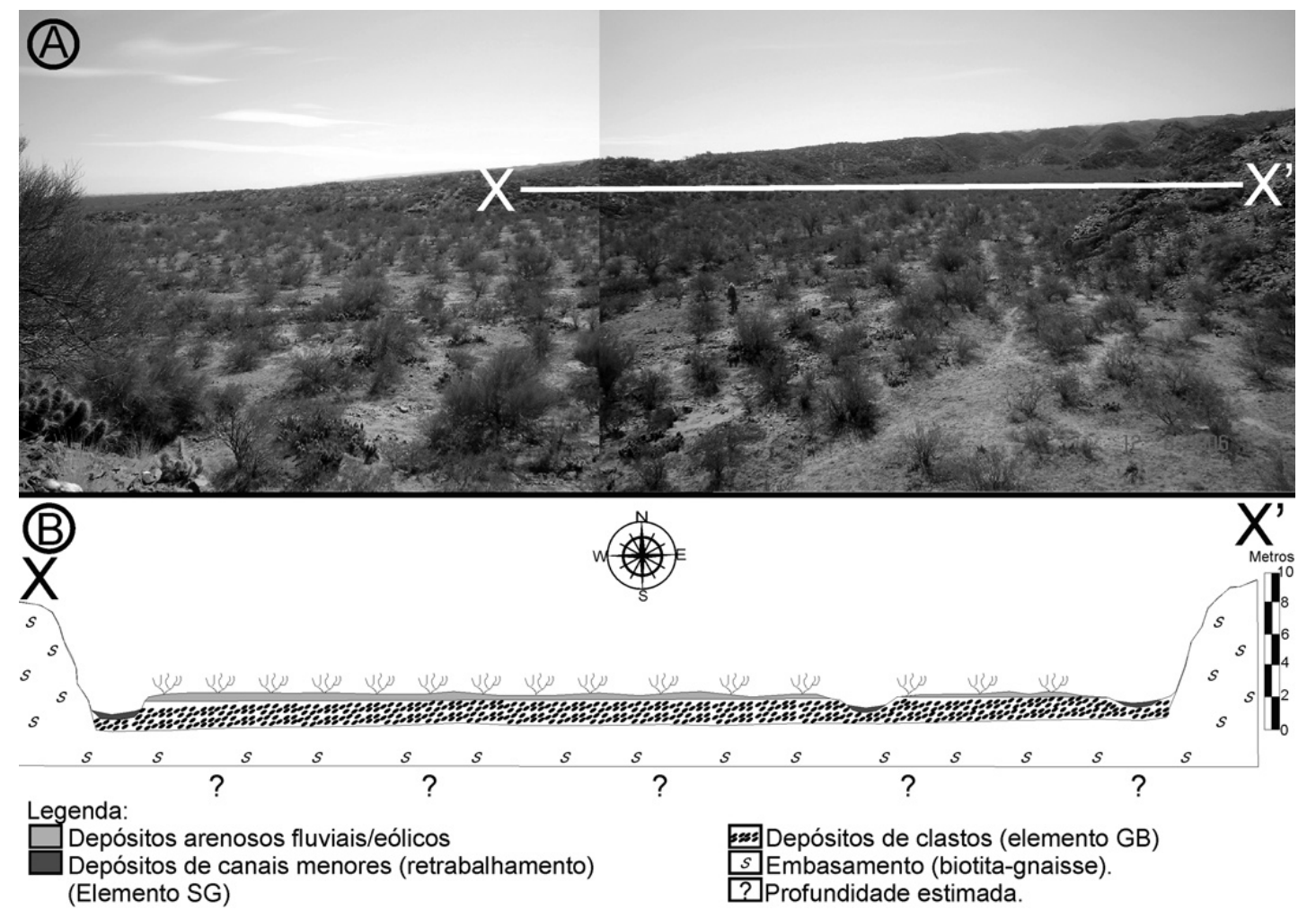

Figura 7 - Vista panorâmica de um canal alimentador do sistema de leques aluviais. A - Vista panorâmica de um canal alimentador do sistema de leques aluviais da Serra de Pie de Palo. $B$ - Esquema mostrando corte transversal em depósitos de fluxos gravitacionais - Elemento GB e SG (Ponto 3 - Fig. 3).

confinados (Fig. 9).

Essa porção do leque é caracterizada pelo espraiamento de grandes lobos cascalhentos com superfície de topo convexa para baixo (4.a ordem) que se estendem por centenas de metros e são retrabalhados por fluxos fluviais efêmeros. As superfícies de 3.a ordem delineiam elementos arquitetônicos do tipo Barra Cascalhentas e Depósitos de Fluxos Gravitacionais (elementos GB e SG) com textura muito grossa, porém, mais fina que aquelas encontradas nos vales de alimentação do leque nas porções proximais à Serra de Pie de Palo. Nessa porção os clastos apresentam arredondamento mais elevado, com considerável aumento na quantidade de areia no arcabouço textural (Fig. 10).

A imbricação dos clastos nessa porção do leque é bastante marcante (Fig. 10). A arquitetura dos depósitos é representada por grandes barras lenticulares e tabulares, que variam de dezenas a centenas de metros de extensão, com ângulo de inclinação da ordem de 1,5 graus para sul.

A quantidade de areia é maior do que nos depósitos confinados pela topografia. Lentes de areia fina a média, com clastos, espessura da ordem de 70 centímetros por alguns metros de comprimento, são observadas no interior e topo dos elementos GB e SG. A fácies arenosa mais freqüente é Am, associada aos níveis superficiais onde existe muita bioturbação por raízes e animais. Subordinadamente ocorre fácies Aea.

Atualmente os depósitos dessa porção do leque estão sendo erodidos e retrabalhados por canais fluviais efêmeros, retilíneos e com poucos metros de largura. Esses canais se estendem por toda a extensão do sistema de leques e até o contato com o Campo de Dunas (classificação segundo Glennie, 1970, para acumulações de areias eólicas com no máximo algumas centenas de $\mathrm{km}^{2}$ ) sofre modificações no seu estilo.

Nas adjacências dos elementos $\mathrm{CH}$ são encontrados alguns depósitos finos, pouco expressivos em área (da ordem de dezenas de metros) onde se concentram sedimentos finos (silte e argila), com gretas de contração, formados após as inundações (Elemento OF - depósitos de planície de inundação) (Fig. 11). Esses depósitos também ocorrem frequentemente na Planície Arenosa (Sand Flat).

Mecanismos deposicionais As associações faciológicas mostram uma diminuição do tamanho dos grãos da cabeceira do leque para jusante. Essa diminuição é decorrente da redução do gradiente topográfico, da diminuição da energia da corrente, do desconfinamento do fluxo e da perda d'água por infiltração e/ou evaporação.

Assim como nos depósitos proximais confinados, os depósitos não-confinados são formados predominantemente a partir de fluxos de detritos não-coesivos, porém, com maior retrabalhamento por fluxos canalizados que se formam nas fases finais dos períodos de inundações.

DEPÓSITOS DISTAIS - DOMINADOS POR FLUXOS TURBULENTOS E LAMINARES (PLANÍCIE ARENO$S A)$ Nas porções mais distais do sistema de leques, 

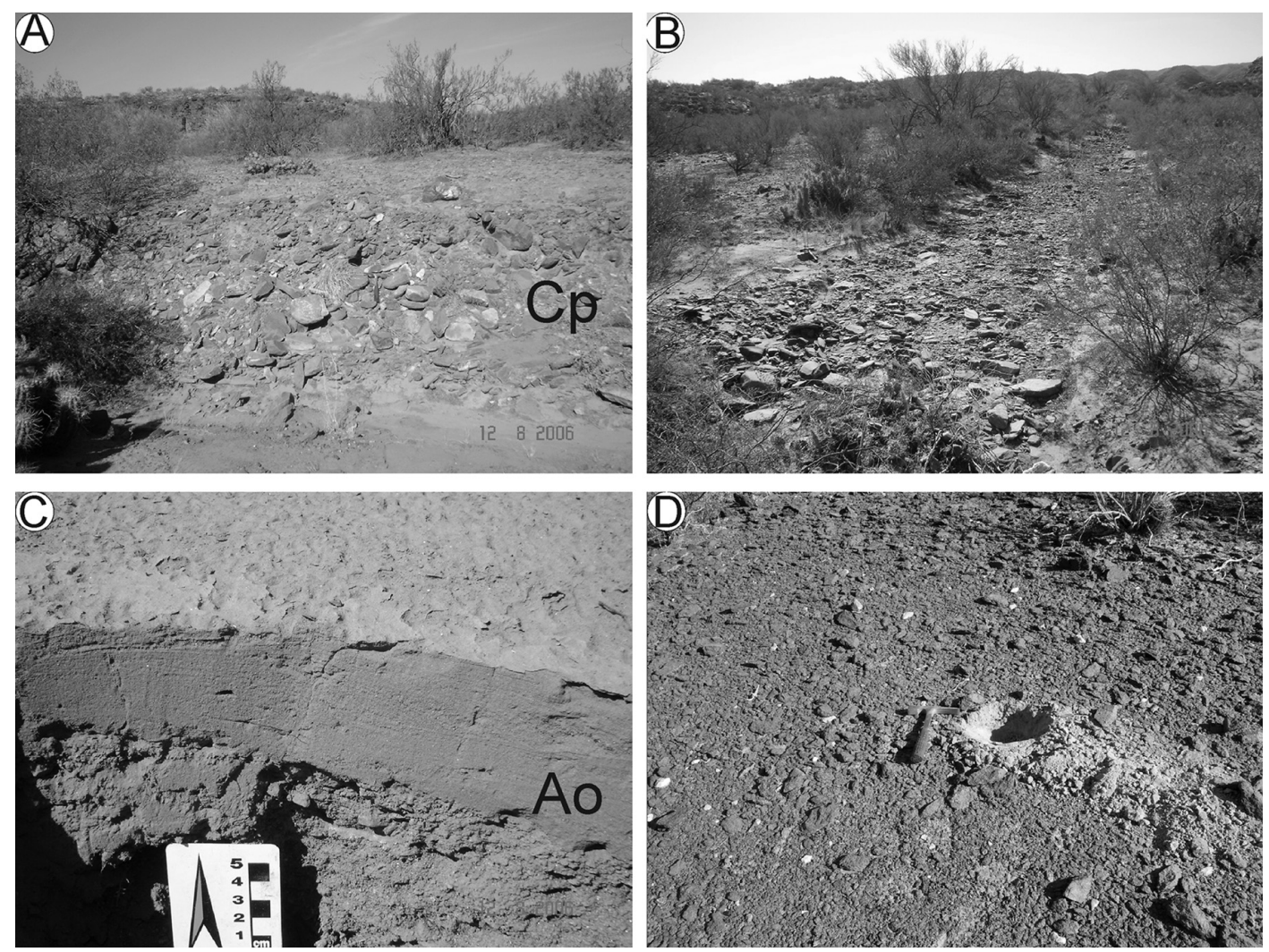

Figura 8 - Depósitos proximais dominados por fluxo de detritos não coesivos. A - Barra cascalhenta (fácies $C p$ ). B-Canal proximal retilíneo cortando os depósitos cascalhentos. $C$ Detalhe da camada arenosa de topo com tênues laminações cruzadas (fácies Ao). D Detalhe do pavimento de clastos gerado por deflação eólica na porção proximal do sistema aluvial (A, B e C Ponto 3; D Ponto 38 - Fig. 3).

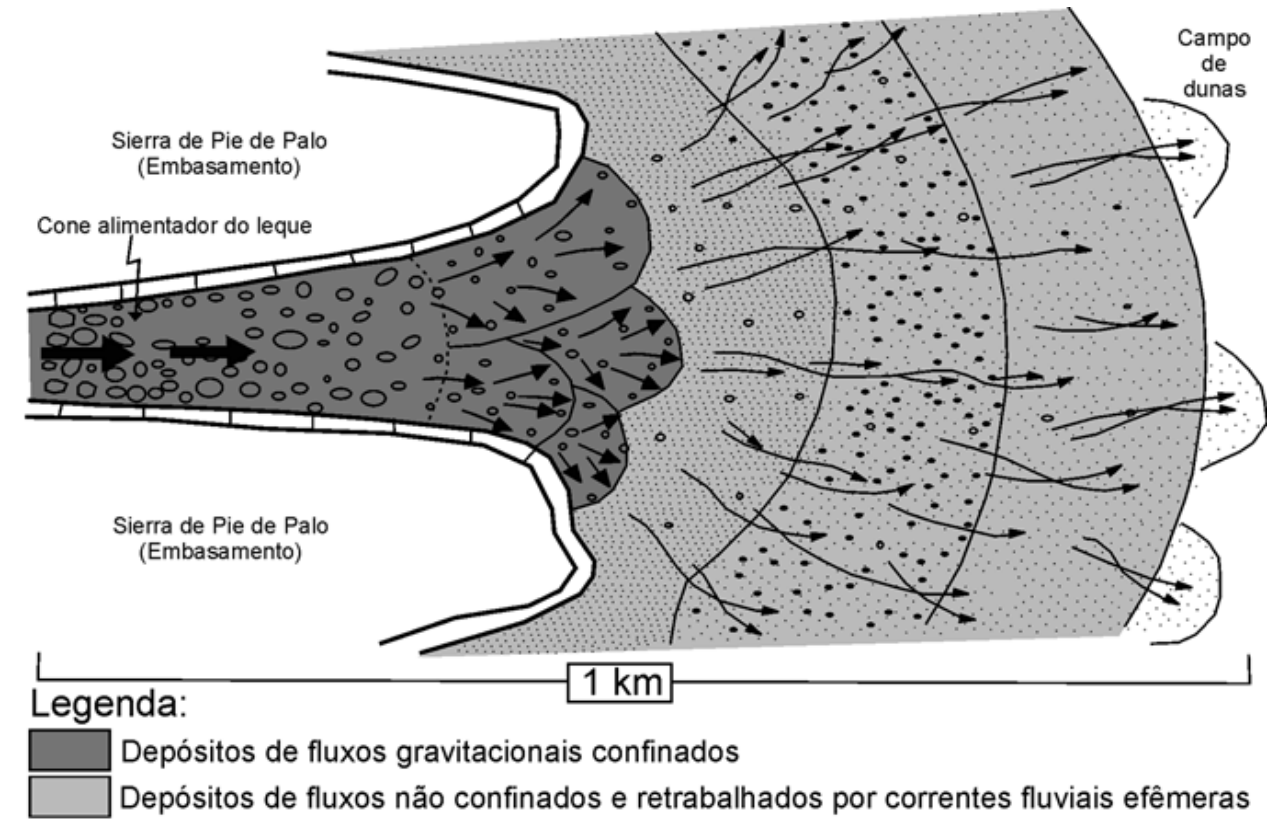

Figura 9 - Vista em planta esquemática mostrando a distribuição dos depósitos confinados e não confinados da porção sul da Serra de Pie de Palo, San JuanArgentina. 

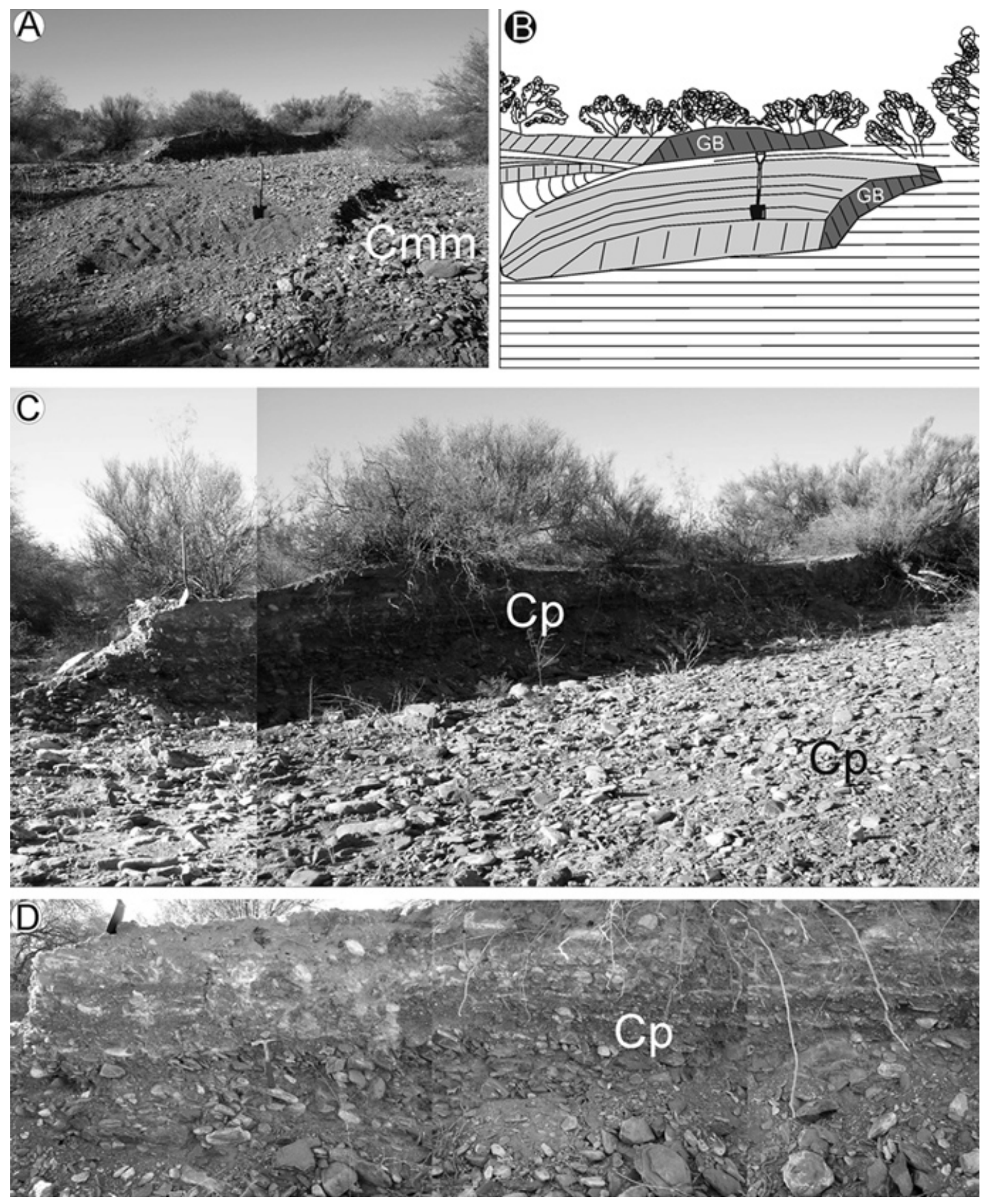

Figura 10 - Características faciológicas do ponto 32. A - Em primeiro plano, barra longitudinal areno-cascalhenta no canal atual. Em segundo plano, depósito cascalhento (Elemento $G B)$ recortado pelo canal atual. B - Esquema do canal e terraço. C-Afloramento expondo barra cascalhenta (elemento GB). Notar imbricação dos clastos no fundo do canal efêmero $D$ - Detalhe do afloramento mostrando clastos imbricados para norte (esquerda para direita). (Ponto 32 - Fig. 3).

onde a declividade do relevo é menor do que 1 grau desenvolve-se uma planície arenosa (Sand Flat), recortada por inúmeros canais fluviais, com aproximadamente $40 \mathrm{~km}^{2}$ de área (Fig. 3). Trata-se da região onde o sistema aluvial começa a interagir com o sistema eólico do Campo de Dunas.

Essa zona geomorfológica é formada por depósitos essencialmente arenosos, com maior maturidade textural e mineralógica, topografia suavemente conve- xa resultante da forte influência de processos fluviais efêmeros e eólicos (Figs. 3 e 11).

Os depósitos fluviais são formados por canais pequenos (da ordem de dezenas de metros de largura), que recortam a Planície Arenosa e retrabalham as areias trazidas do Campo de Dunas. São canais entrelaçados, com baixa a média sinuosidade, onde predominam as fácies Aea, Am, Alp, Ao, Fma, Cea, Cmm e Cmg.

No interior dos canais ocorrem mesoformas que 

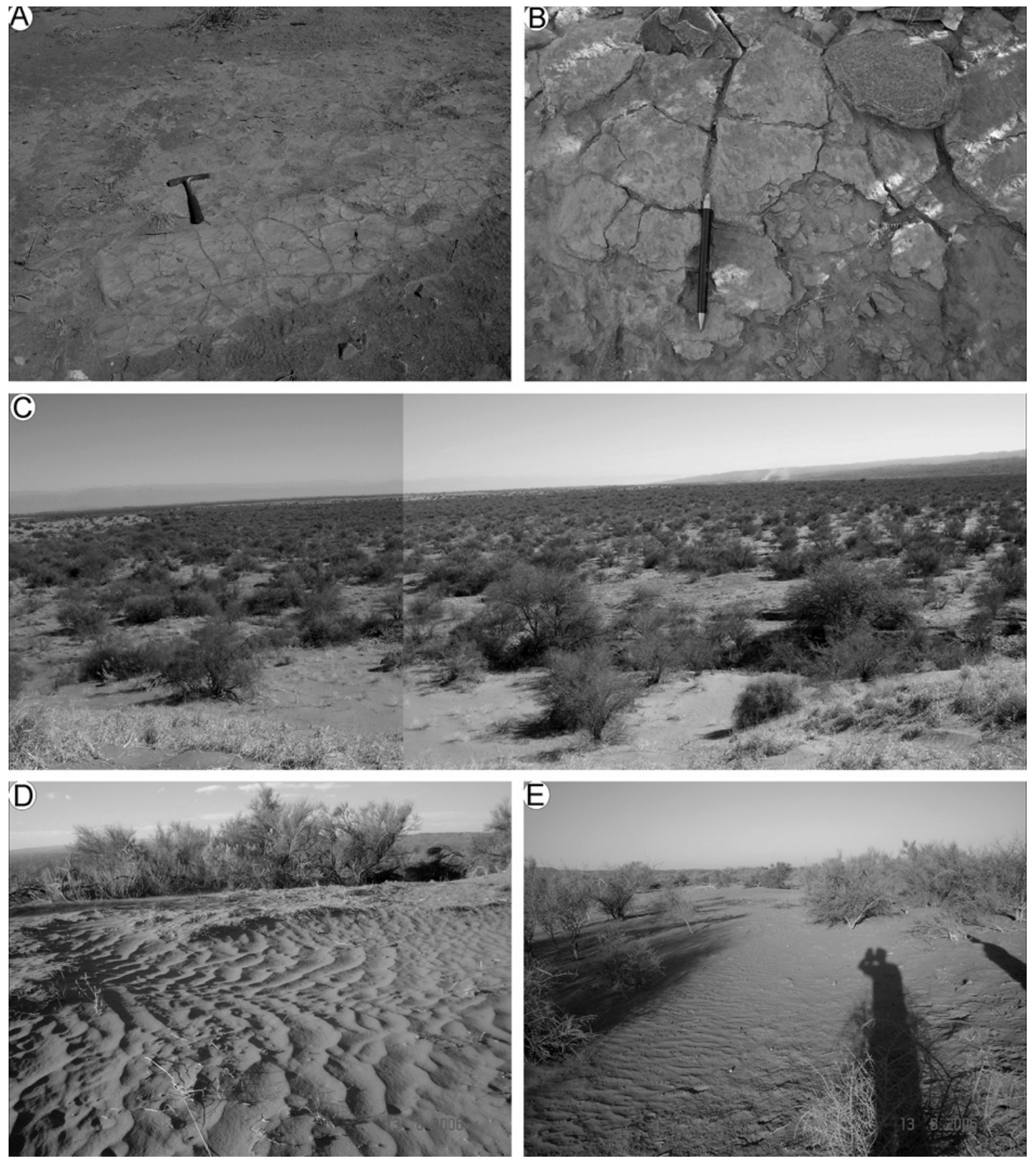

Figura 11 - Características faciológicas da planície arenosa. A - Depósito lamítico de planície de inundação (elemento OF). B - Detalhe das gretas de ressecamento. (Ponto 13 - Fig. 3). C - Vista panorâmica da porção distal do sistema de leques aluviais (Planície Arenosa) e início do Campo de Dunas (esquerda) (Ponto 13 - Fig. 3). D-Marcas onduladas pelo vento (wind ripples) (Ponto 9 -Fig. 3). E-Marcas onduladas e pavimentos de seixos gerados por deflação eólica (Ponto 9 - Fig. 3).

são partes integrantes de macroformas de acréscimo lateral (elemento LA) e acréscimo à jusante (elemento DA), sendo estas limitadas por superfícies hierárquicas de 3.a ordem. Superfícies hierárquicas de 1.a e 2.a ordens são aquelas que correspondem às estratificações cruzadas das areias e aos cosets que limitam as mesoformas de leitos arenosas e areno-cascalhentas, respectivamente (Fig. 12).

As fácies Cmg e Cmm ocorrem na base do elemento de canal $(\mathrm{CH})$ ou como barras longitudinais cascalhentas com espessura da ordem de 50 centímetros. São constituídas por clastos de diâmetros que variam entre seixos e calhaus, arredondados a subarredonda- dos, com quantidade de matriz arenosa que varia entre 20 e $30 \%$, que se concentram em pavimentos maciços nos leitos dos canais, com espessura da ordem de 40 centímetros (Figs. 13, 14 e 15).

A fácies Cea é constituída por grânulos e seixos misturados com areia grossa a muito grossa, limitada por superfícies de 2.a ordem, formando barras no interior dos elementos de canais, onde os fluxos tracionais são capazes de mover os clastos (seixos) por arrasto ou rolamento e depositá-los nas camadas frontais (foresets) de estratos cruzados. Essa fácies ocorre associada às fácies arenosas nos depósitos de canais e nas macroformas de acréscimo lateral e à jusante (Elementos LA 
e DA) (Fig. 12 - B).

A fácies Aea é formada por areia fina a média, seleção moderada, por vezes associada às fácies cascalhentas (Cmg, Cmm e Cea) como a porção fina de ciclos granodecrescentes ascendentes, ou como mesoformas dentro dos Elementos DA e LA (Macroformas de acréscimo à jusante e lateral). Como característica marcante, apresenta camadas frontais muitas vezes definidas por seixos e/ou grânulos (Figs. $12 \mathrm{C}$ e D).

A fácies Aeab é bastante comum nos depósitos de dunas eólicas adjacentes aos canais. Trata-se do elemento SS (Chrintz \& Clemmensen, 1993). Nesses depósitos, a fácies apresenta textura mais fina e grau de seleção dos grãos bom a moderado. Os clastos são arredondados e, devido ao retrabalhamento eólico, apresentam-se foscos. As estratificações cruzadas são de pequeno a médio porte (camadas frontais com até 3 metros de comprimento), e seu ângulo de inclinação é da ordem de 15 graus. Em alguns locais a inclinação das camadas frontais (foresets) é tão baixa que chega a ficar horizontal (Fig. 15).

É comum encontrar a fácies Aeab associada à lentes e/ou camadas de cascalho (fácies $\mathrm{Cmg}$ ) com espessura da ordem de 30 a 40 centímetros, bem como delgadas camadas de argila com gretas de contração e estrutura teepee (Fig. 15).

Nas porções arenosas superiores dos ciclos granodecrescentes ascendentes a granulometria diminui para fina a muito fina, formando camadas com até 30 centímetros de espessura, com muitas laminações cruzadas originadas por tração dos sedimentos em regime de fluxo inferior (marcas onduladas) (Simons et al., 1965). Essas feições são características marcantes da fácies Ao e são geradas a partir da desaceleração da velocidade dos fluxos aquosos que transportam os sedimentos nos estágios finais das chuvas efêmeras (Fig. 16).

A fácies Alp é constituída por areias finas a médias, seleção boa a moderada, clastos sub-arredondados, pouca matriz argilosa (aproximadamente 10\%), com estratificação plano-paralela. (Fig. 16). Ocorre associada à fácies $\mathrm{Cmg}$ em ciclos granodecrescentes ascendentes.

Essa fácies ocorre também associada às fácies Fma e Ao nas planícies de inundação adjacentes aos elementos de canal. Nesses locais, essa fácies é mais fina, e comumente, apresenta lâminas de argila. No seu topo é freqüente encontrar gretas de ressecamento.

A fácies Am, assim como em outras porções da
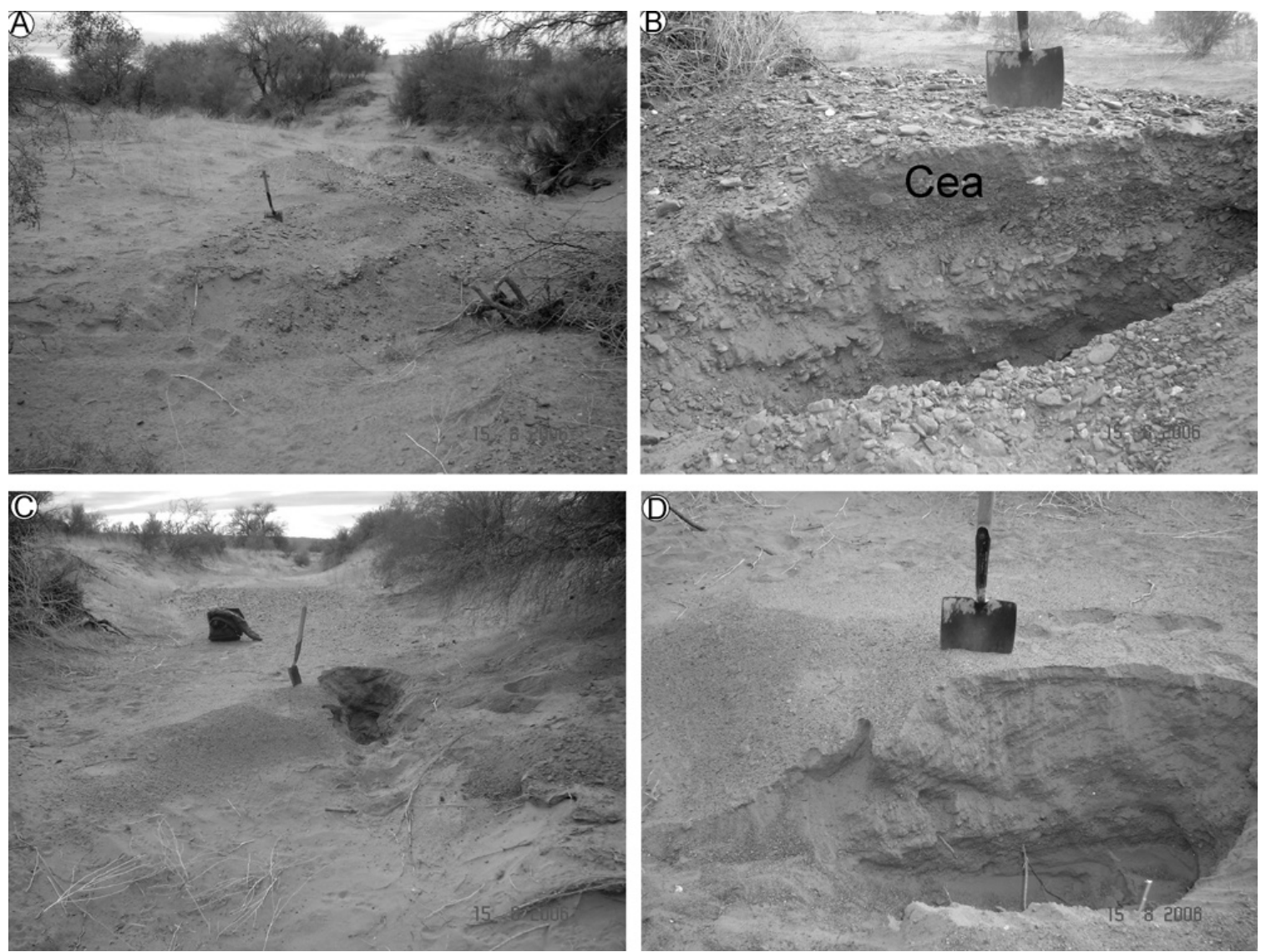

Figura 12 - Elementos arquitetônicos fluviais na porção distal do sistema de leques (Ponto 23 - Fig. 3). A - Macroforma de acréscimo lateral (Elemento LA). B - Detalhe da estratificação cruzada (Superficies de 2.a e 3.a ordens) (Ponto 23 - Fig. 3). C-Mesoforma de topo de uma macroforma de acréscimo à jusante (Elemento DA). D-Detalhe das estruturas internas (foresets e cosets) da mesoforma (Ponto 23 - Fig. 3). 


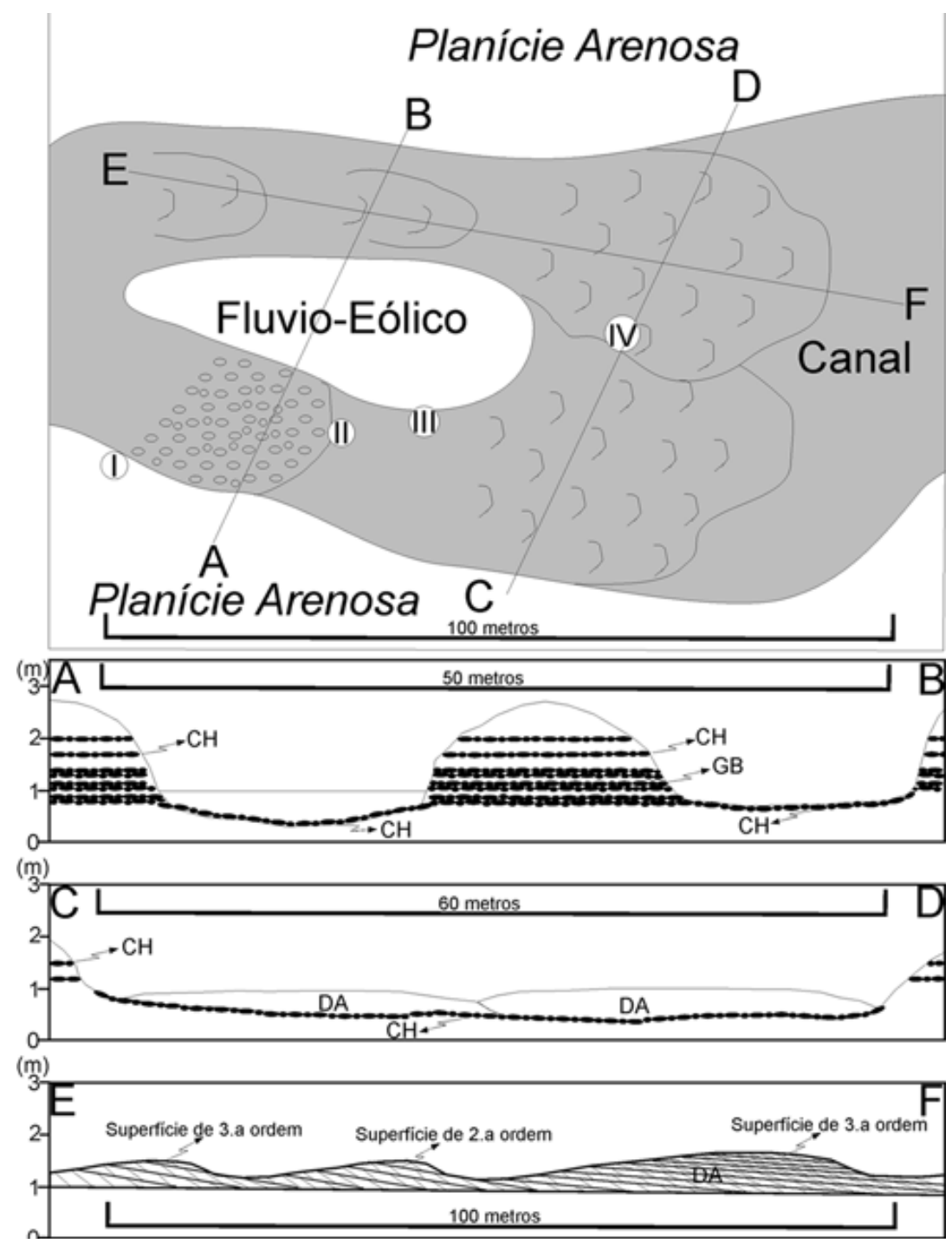

Figura 13 - Esquema mostrando o Elemento Canal (CH) no ponto 23 (Fig. 3). Distribuição das fácies e elementos arquitetônicos em 2 cortes transversais $(A-B$ e $C-D)$ e 1 longitudinal $(E-F)$ ao canal.

área de estudo, aparece com mais freqüência formando camadas de topo, associadas a todas as fácies. Trata-se de areias sob processo de pedogênese, bioturbadas por raízes e animais que constroem túneis (Fig. 14A).

As camadas de topo formadas por essa fácies são irregulares e pouco espessas, acompanhando a topografia do terreno. Embora mais freqüentes na superfície, a fácies Am aparece também intercalada às demais fácies arenosas da Planície Arenosa, atestando a geração de solos recentes que limitam ciclos deposicionais.

Nas planícies formadas nos interflúvios é comum encontrar depósitos de dunas baixas com aproximadamente $50 \mathrm{~cm}$ de altura e comprimentos de onda que variam entre 2 a 5 metros, conferindo à topografia um caráter suavemente ondulado. Nessa porção da Planície Arenosa são freqüentes camadas contínuas da fácies Am, bem como pavimentos de clastos (seixos) sobre os depósitos arenosos, resultantes da deflação eólica (Fig. 16).
Em cortes de trincheiras pouco profundas escavadas nessa região, observa-se que os depósitos arenosos da Planície Arenosa são pouco espessos, da ordem de 2 a 3 metros, sendo que estes recobrem depósitos cascalhentos proximais (fácies $\mathrm{Cmm}, \mathrm{Cgm}, \mathrm{Cp}$ ). Internamente, intercalam-se com camadas cascalhentas com $30 \mathrm{~cm}$ de espessura, sustentados por matriz e por clastos, geometria lenticular, resultantes de retrabalhamento por fluxos fluviais efêmeros (Figs. 13 e 16).

Mecanismos deposicionais $\mathrm{O}$ padrão entrelaçado dos canais encontrados nessa porção da área de estudo é originado do acúmulo de areias e cascalhos em seu leito, oriundos da área fonte próxima e dos depósitos eólicos adjacentes à planície aluvial. Os inúmeros canais se dividem em uma rede de distributários e o desenvolvimento de barras reduz progressivamente a capacidade do sistema de transportar água, causando assim, rompimentos dos diques marginais durante cheias e 

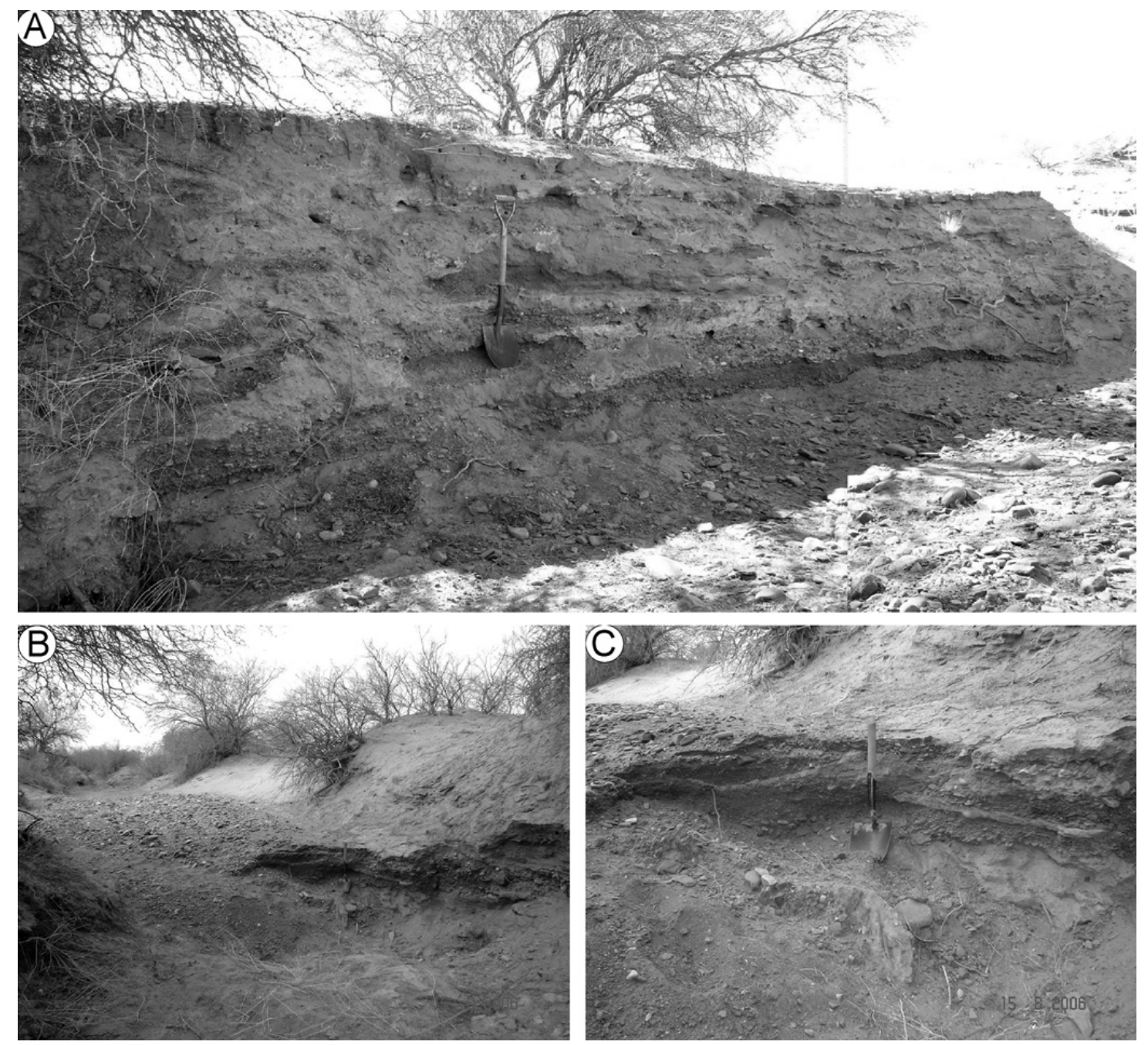

Figura 14 - Características faciológicas de depósitos de canais e dunas na planície arenosa. A - Afloramento expondo as fácies Cmm, Cmg e Am muito bioturbado por raizes (local I-Fig. 13). B - Canal menor expondo a fácies Am intercalada pela fácies Cmg (local II - Fig. 13). CDetalhe das fácies da foto B (local II - Fig. 13).

processos de avulsão. Sendo assim, uma das principais características da área são as mudanças abruptas de leito, gerando centenas de canais abandonados.

As fácies descritas indicam transporte dos sedimentos predominantemente por fluxos turbulentos gerados pelas enxurradas durante o período de chuvas torrenciais, que descem da Serra de Pie de Palo rumo à Planície Arenosa. Onde a topografia é mais inclinada, próximo ao sopé da montanha, a mistura de sedimento e água produz movimentos de massa (fluxos de detritos e fluidificado) confinados ou não em canais.

À medida que esses fluxos de massa percorrem as porções com menor declividade, perdem gradativamente a energia de transporte e os sedimentos se depositam. A água, então com menor quantidade de sedimentos e menor velocidade que nas cabeceiras, passa para um fluxo turbulento.

Embora com menos sedimentos grossos, os fluxos que recortam a Planície Arenosa ainda possuem competência suficiente para transportar muita areia e cascalho. A diminuição progressiva da declividade do relevo gera decréscimo de energia, e o material transportado se deposita.

Nos canais (Elemento $\mathrm{CH}$ ), onde os fluxos são mais intensos, as correntes de tração (sob regime de fluxo superior de Simons et al., 1965) são capazes de transportar e depositar clastos de diâmetros que variam entre seixos e calhaus, formando as fácies $\mathrm{Cmg}, \mathrm{Cmm}$ e $\mathrm{Cp}$.

A fácies Aea que compõem as macroformas de acréscimo lateral e à jusante (Elementos LA e DA), são resultantes de correntes de tração menos energéticas (regime de fluxo inferior de Simons et al., 1965), geradas em estágios finais do período de chuvas.

A fácies Aeab provavelmente tem sua origem relacionada ao retrabalhamento de depósitos eólicos por fluxos aquosos, também nas fases menos energéticas. A presença de vegetação na Planície Arenosa não permite que os ventos atuem com muita intensidade gerando grandes dunas.

A fácies Alp, quando associada às fácies $\mathrm{Cmm}$ e Cmg, indica deposição a partir de fluxos mais energéticos capazes de gerar formas de leitos planos carac- 

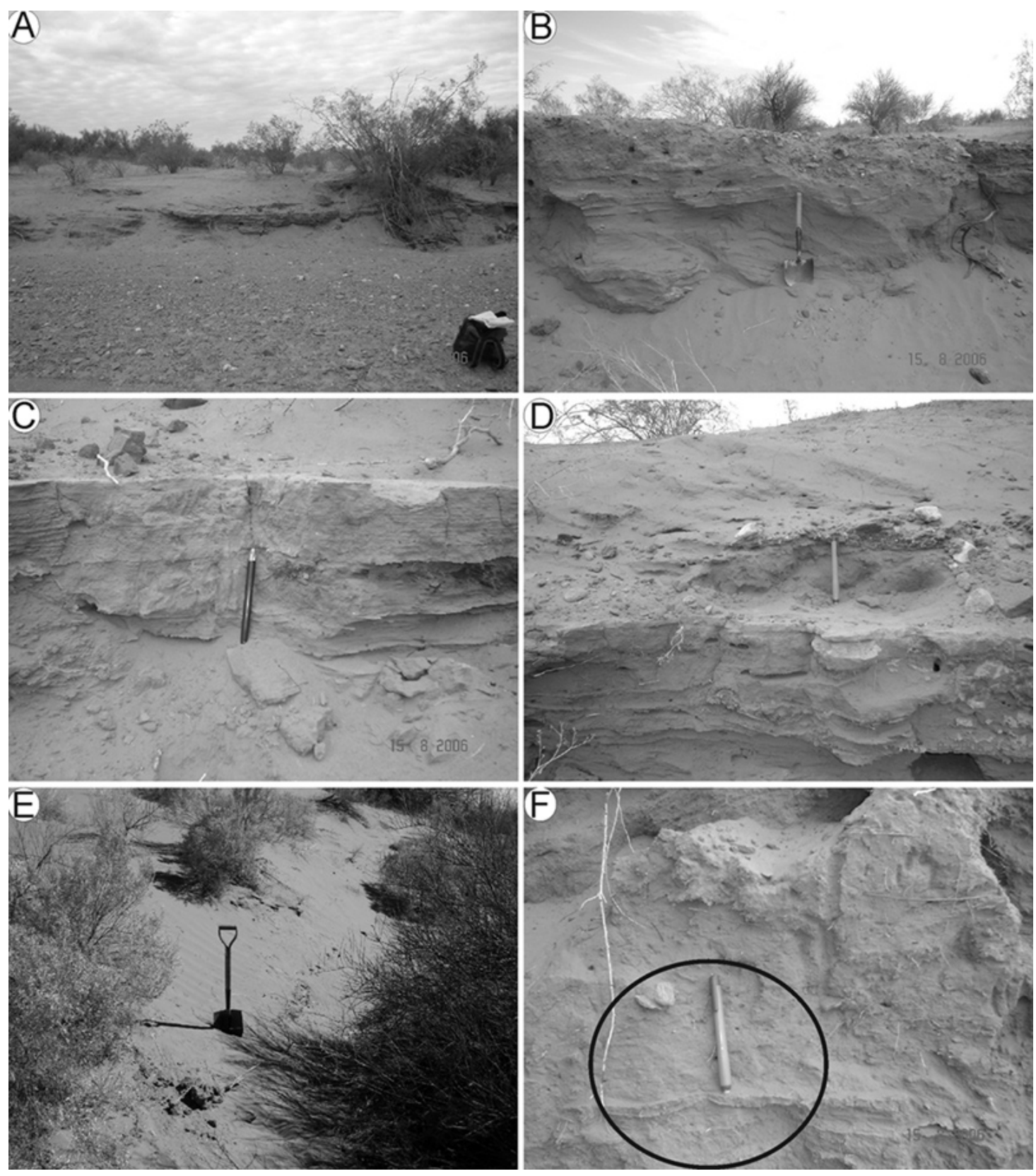

Figura 15 - Características faciológicas de depósitos de canais e dunas na planície arenosa. A-Afloramento mostrando a fácies Aeab em corte de canal. B-Detalhe das estratificações cruzadas de baixo ângulo. C-Detalhe das laminações sub-horizontais. $D$-Detalhe da fácies Aeab com lentes da fácies Cmg intercaladas. E-Depósito eólico migrando sobre a fácies Cmg. $F$ - Detalhe de uma camada lamítica com estrutura teepee (base da lapiseira). (Pontos 16 e 17 - Fig. 3).

terísticos de regime de fluxo superior (Simons et al., 1965). Provavelmente esses depósitos são resultantes de fluxos em lençol de areia laminado (Elemento LS Miall, 1996)

Já a associação entre as fácies Alp, Ao e Fma, com delgadas camadas lamíticas com gretas de contração indica deposição sob condições de muito baixa energia, constituindo depósitos de "overbank" (elemento $\mathrm{OF}$ ) em planícies ou pequenas lagoas formadas pelas inundações nas adjacências dos canais, nos períodos de relativa calmaria após as chuvas (Figs. 11A e 14B).
DISCUSSÃO E COMPARAÇÃO COM SISTEMAS ANTIGOS A análise de fácies acima apresentada, muito embora prejudicada pela falta do conhecimento sobre a relação entre a variabilidade temporal e espacial dos depósitos, permite elaborar um modelo que contempla a distribuição e ligação genética entre as zonas geomorfológicas de um sistema aluvial de clima árido.

Conforme Sawakuchi \& Giannini (2006), diversos modelos de fácies são elaborados a partir de sistemas deposicionais recentes (com duração de dezenas a poucas centenas de milhares de anos), sendo freqüente o uso destes modelos para descrever e interpretar de- 

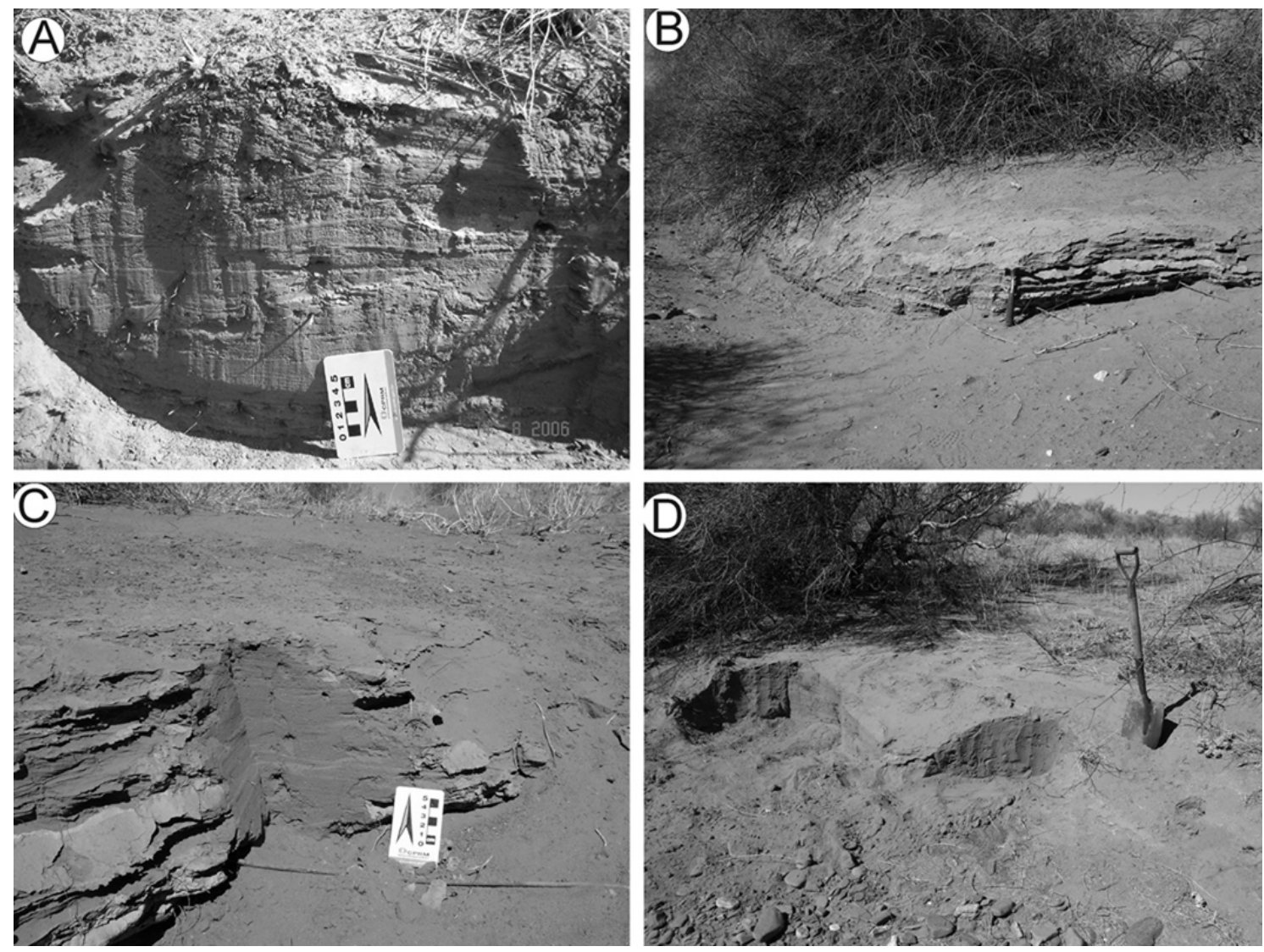

Figura 16 - Fácies Ao e Alp. A - Detalhe da laminação cruzada (Ponto 31 - Fig. 3). B e CFácies Alp (Ponto 18 - Fig. 3). Notar pavimento de clastos sobre o depósito arenoso. D - Vista panorâmica da topografia suavemente ondulada e estratos cruzados de baixo ângulo (fácies Aeab) (Ponto 31 - Fig. 3).

pósitos cujo intervalo de tempo de formação alcança dezenas de milhões de anos. Nesse sentido, a observação da dinâmica destes sistemas em curto período de tempo não permite compreender as sucessões de fácies que formam o registro estratigráfico.

Embora os sistemas aluviais analisados sejam geograficamente e temporalmente restritos, o que os torna mais sensíveis às mudanças de intensidade pequena $\mathrm{e}$ de curta duração, os depósitos formados refletem a forte influência das condições tectônicas e climáticas, que podem ser usados como modelos de comparação com bacias antigas. Evidentemente que tal comparação deve ser ponderada, sobretudo no que diz respeito ao preenchimento das bacias, uma vez que o registro é descontínuo.

A partir desta óptica, a análise dos depósitos holocênicos do oeste argentino e seus respectivos mecanismos deposicionais permitiu identificar muitas feições faciológicas semelhantes às encontradas nos registros cretáceos da Bacia Bauru. Embora não apresentados nesse trabalho, os dados de afloramentos usados para comparação podem ser contemplados em Batezelli et al. (2007).

$\mathrm{Na}$ área usada para comparação, na porção norte e noroeste da Bacia Bauru, existe um domínio de canais (elementos $\mathrm{CH}$ ) e formas de leito arenoso (elemento $\mathrm{SB}$ ). Canais maiores (elemento de $\mathrm{CH}$ - intermediário) na Bacia Bauru são marcados na base por superfícies de 4. a ordem com suave concavidade para o topo, enquan- to, que os canais menores geralmente são delimitados por superfícies de 3.a ordem. Nesse caso, além da dimensão, a associação faciológica e os elementos arquitetônicos menores permitiram identificar os diferentes tipos de canais na área de estudo. A associação de fácies $\mathrm{Cmm}$ e Cmg com gradação normal ou inversa, em camadas espessas é característica de fluxos de massa e fluxos de detritos associados a eventos de sedimentação rápida e de alta energia (processos gravitacionais), é encontrada principalmente no elemento SG na Bacia Bauru. Essas características são comuns de depósitos proximais de leques aluviais, onde a inclinação é maior do que $9^{\circ}$, conforme observadas nas seções descritas nos depósitos atuais do Vale do Rio Jáchal e da Serra de Pie de Palo (Figs. 4, 7 e 8).

$\mathrm{Na}$ rodovia que liga Quirinópolis $(\mathrm{GO})$ a Rio Verde (GO), a km 39 de Quirinópolis (Batezelli et al, 2007), a fácies Cea está associada às fácies $\mathrm{Cmm}, \mathrm{Cmg}$, Am e Aea, formando um estrato com mais de 20 metros de espessura. Nesse ponto são comuns feições deformacionais (injeções de areia), gradações normais e inversas, indicativas de processos gravitacionais. As estratificações cruzadas acanaladas dessa fácies são típicas de depósitos de barras clastosas longitudinais (Miall, 1985; 1988a e b; 1996). Essas feições são semelhantes às encontradas nos depósitos do Vale do Rio Jáchal e Serra de Pie de Palo. Porém, nos depósitos brasileiros, 
a arquitetura dos corpos é mais organizada, indicando um retrabalhamento maior por fluxos fluviais (elementos GB).

Macroformas de acréscimo à jusante (Elemento DA) são comuns na região de Uberaba (MG) (Batezelli, 2003, Batezelli et al., 2007).

O elemento SB nos depósitos brasileiros inclui extensas superfícies com marcas onduladas e dunas menores (fácies Aeh, Aea e Aet) cuja gênese está relacionada ao desenvolvimento de barras formadas a partir da migração de formas de leito de canal a jusante, ou ao topo de barras formadas por fluxos em lençol de leques de arrombamento (crevasse splays).

Conforme mencionado por Batezelli et al. (2007) as formas de leito descritas no elemento SB podem ter sido formadas também a partir de processos eólicos. Nas seções AB-01, AB-04 e AB-05, a fácies Alp apresenta características texturais sugestivas de ter sido formada por migração de micro dunas transportadas por vento (translated climbing ripples de Hunter, 1977) em que o lie side não se preserva, e cujo resultado final são areias finas com laminações plano-paralelas. Nesse caso, corresponderiam ao elemento SS descritos na Planície Arenosa do Deserto de Pie de Palo.

$\mathrm{O}$ elemento arquitetônico LS (lençol de areia laminado) encontrados tanto na Bacia Bauru como no Vale do rio Jáchal, embora parecidos do ponto de vista de texturas e estruturas sedimentares, apresentam características distintas em relação aos mecanismos deposicionais.

Nos depósitos brasileiros o elemento LS, constituído pelas fácies $A l p$, Aeh e Am, geralmente é pouco espesso, textura fina a média e características que sugerem sua gênese associada a depósitos extra canal gerados em períodos de enchente. São depósitos em forma de lençóis de areia laminados que podem ter depósitos de transbordamento (overbank) (elemento OF) associados, formados em planícies de inundação ou em canais abandonados por fluxos esporádicos. Sua geometria, definida por superfícies erosivas irregulares, endossa essa interpretação de deposição por fluxos efêmeros.

No entanto, na maioria dos afloramentos do Vale do Rio Jáchal os elementos LS apresentam características faciológicas (textura muito fina, marcas onduladas, moldes de cristais salinos) que sugerem outros mecanismos deposicionais, principalmente, processos sedimentares associados a decantação e fluxos tracionais muito diluídos (turbiditos distais), em porções distais de sistemas lacustres rasos e efêmeros (playa lakes).

Sendo assim, a utilização do termo "lençol de areia laminado" para o elemento arquitetônico LS descrito no Vale do Rio Jáchal, não condiz com a proposta original de Miall (1985, 1988a e b; 1996). Propõe-se aqui a designação do termo LSp para os depósitos de areia laminados cuja gênese esteja associada a bacias receptoras endorreicas, efêmeras, do tipo playa lakes. Constata-se que as fácies que compõem o elemento $L S p$ no Vale do Rio Jáchal (Argentina) são comparáveis a algumas encontrados em outras partes da Bacia Bauru, sobretudo aos depósitos que constituem a Formação
Araçatuba no Estado de São Paulo (Batezelli, 1998; Batezelli et al., 2003; Batezelli et al., 2006).

Em relação aos depósitos holocênicos do Deserto de Pie de Palo, mesmo se tratando de uma escala mais detalhada de observação, verifica-se grande semelhança com os estudados por Batezelli et al (2007) na porção norte e noroeste da Bacia Bauru.

Nos depósitos formados a partir de fluxos de detritos não-coesos (fácies $\mathrm{Cp}, \mathrm{Cmm}$ e Cmg - Elementos GB e SG), encontrados nas proximidades e reentrâncias topográficas da Serra de Pie de Palo, a textura sedimentar é mais grossa, predominando clastos de diâmetros de calhaus e matacões, com forma muito angulosa, baixa quantidade de matriz arenosa e imbricação de clastos marcante (Fig. 8).

As fácies Cmm e Cmg descritas no Grupo Bauru (Ponto AB-03 - Batezelli et al, 2007) apresentam textura mais fina, clastos mais arredondados e estão associadas às fácies Cea e Am. Já a fácies $\mathrm{Cp}$ não foi encontrada no Grupo Bauru.

Os correspondentes da associação faciológica $\mathrm{Cp}, \mathrm{Cmm}$ e $\mathrm{Cmg}$ na Bacia Bauru, provavelmente não se preservaram pelo fato de que a atividade tectônica no Soerguimento do Alto Paranaíba (Hasui \& Haralyi, 1991) e na Província Alcalina de Goiás (JunqueiraBrod et al., 2002) foi muito intensa após a fase final de sedimentação na bacia, o que propiciou sua erosão.

Os depósitos holocênicos do Deserto de Pie de Palo formados dominantemente por fluxos turbulentos e laminares são constituídos pelas fácies Aea, Am, Alp, Ao, Fma, Cea, Cmm e Cmg, sendo que suas características sedimentológicas, bem como a distribuição em área, apresentam muita semelhança com os depósitos da Bacia Bauru. A Planície Arenosa é marcada por muitos elementos de canais $(\mathrm{CH})$ que recortam a planície aluvial, hoje afetada por processos pedogenéticos em virtude da baixa taxa de sedimentação e desenvolvimento de vegetação arbustiva.

A fácies Cea, tanto para os depósitos do Deserto de Pie de Palo, como para o Grupo Bauru, é caracterizada por cascalhos cujos seixos são arredondados, arcabouço sustentado por matriz arenosa média a grossa, com estratificações cruzadas acanaladas de pequeno a médio porte, limitadas por cosets convexos (superfícies de 2.a ordem), associadas aos elementos de canal $(\mathrm{CH})$ e Macroformas de Acréscimo Lateral (LA) e à Jusante (DA) (Fig. 12).

Outro aspecto comum entre as duas áreas é constatada nas características sedimentológicas e distribuição da fácies Alp. No Deserto de Pie de Palo, essa fácies foi descrita principalmente nos depósitos onde os elementos de canal interagem com os elementos eólicos (Figs. 15 e 16).

Entre todas as semelhanças observadas em ambas as áreas, a mais marcante diz respeito às camadas contínuas da fácies Am. No Deserto de Pie de Palo essa fácies aparece em vários níveis estratigráficos intercaladas às fácies $\mathrm{Cp}, \mathrm{Cmg}, \mathrm{Cmm}$, Cea e Aea, ou no topo das seqüências coincidindo com a superfície topográfica da Planície Arenosa. 
Sua espessura é variável, podendo atingir mais de 1 metro em alguns pontos, principalmente nos interflúvios, e sua origem intimamente ligada aos processos pedogenéticos atuais sobre os depósitos eólicos/aluviais da Planície Arenosa.

$\mathrm{Na}$ Bacia Bauru a fácies Am apresenta espessuras bem maiores do que as do Deserto de Pie de Palo, chegando a dezenas de metros. Internamente às espessas camadas maciças observam-se várias superfícies que limitam ciclos menores de gênese de paleossolos (Fig. 17).

Do ponto de vista paleogeográfico, o modelo de sedimentação no Vale do Rio Jáchal na Argentina contempla um cenário que engloba fácies proximais e distais de um sistema de leques aluviais coalescentes. Nesse sistema os leques adentram a bacia receptora, localizada no sopé de grandes cadeias de montanhas (PréCordilheira Argentina), recortando depósitos holocênicos finos formados em um ambiente lacustre raso, sob condições de clima árido (playa lake).

Já a maior parte dos depósitos do Grupo Bauru descritos na área de estudo, por sua vez, reflete processos sedimentares de menor energia, relacionados a um
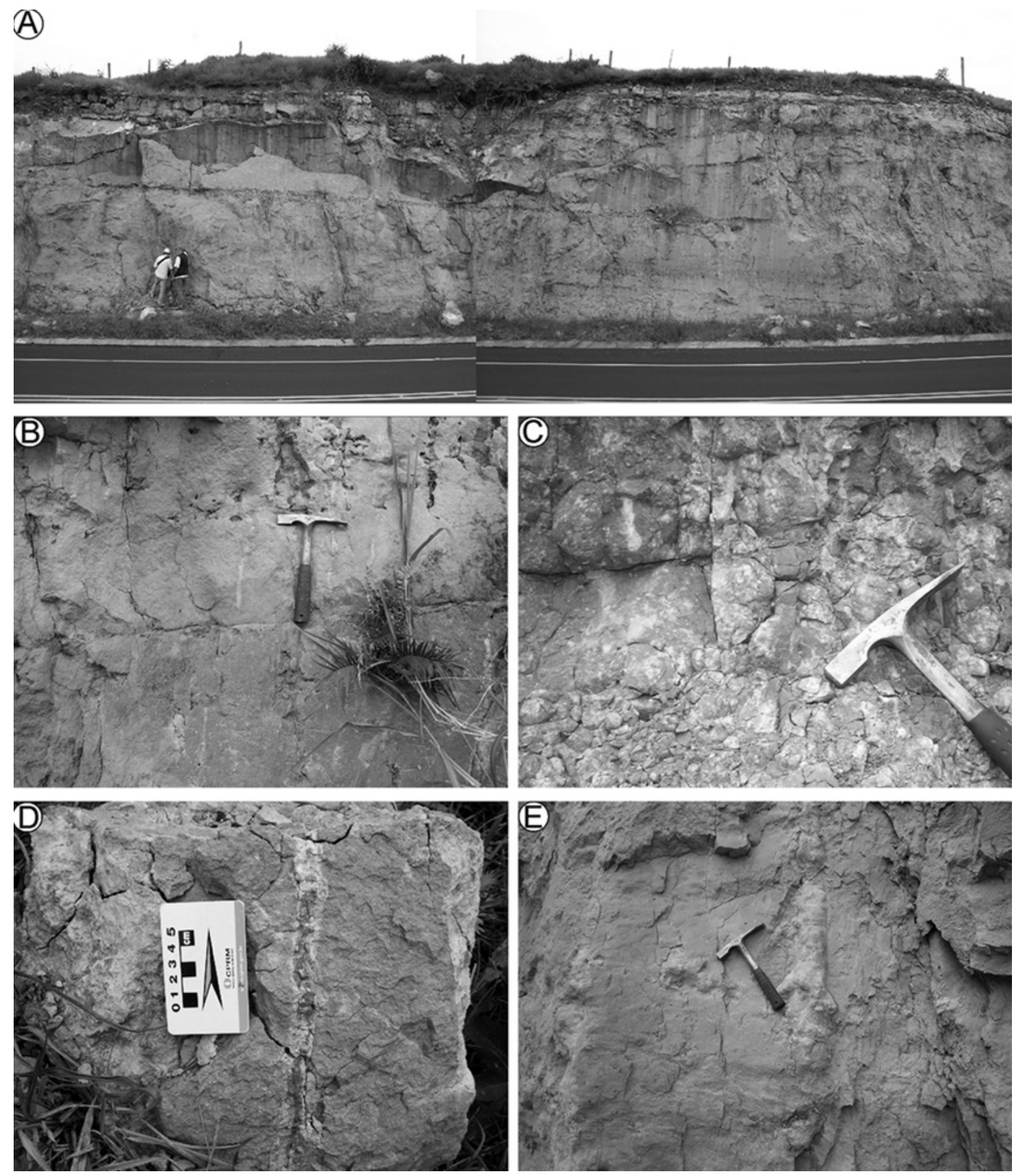

Figura 17 - Aspectos paleopedogenéticos da Formação Marília na Bacia Bauru - A - Afloramento expondo espessa camada da fácies Am. B - Contato entre 2 niveis de paleossolos. $C$ Detalhe do mosqueamento e marcas de raizes da fácies Am. D - Marca de raiz preenchida por carbonato de cálcio. E- Marca de raiz com 2 metros de comprimento preenchida por carbonato de cálcio. (Rodovia Marília-Echaporã, $5 \mathrm{~km}$ de Echaporã - SP). 
sistema aluvial cujo cenário contemplava uma extensa planície com rios entrelaçados, de baixa sinuosidade, onde ocorria retrabalhamento eólico e desenvolvimento de paleossolos. Nesse caso, a extensa planície aluvial teria dimensões superiores a $300 \mathrm{~km}^{2}$, e separava as porções proximais dominadas por depósitos gerados por fluxos gravitacionais (elementos $\mathrm{SG}, \mathrm{GB}$ e $\mathrm{CH}$ ), das porções distais (depósitos finos de origem lacustre rasa - playa lake) (elementos LSp).

As fácies e elementos arquitetônicos descritos na área de estudos usada para comparações no Deserto de Pie de Palo no oeste argentino, apesar de restritas, apresentam maior semelhança com os depósitos neocretáceos brasileiros da Bacia Bauru.

Informações futuras oriundas de análises petrográfica e paleopedológica, preencherão lacunas importantes sobre os conceitos sedimentológicos e estratigráficos da bacia, permitindo delinear as áreas favoráveis à gênese e evolução de diferentes tipos de paleossolos, suas relações com as feições paleoestruturais e posicionamento paleogeomorfológicos, limites de seqüências estratigráficas, podendo chegar ao nível de tecer considerações detalhadas sobre períodos com oscilações pluviométricas e acumulação de água no solo.

Agradecimentos A Fundação de Amparo à Pesquisa do Estado de São Paulo - FAPESP pelo apoio financeiro ao projeto 04/13387-1 "Aplicação de um Modelo Atualístico na Caracterização Deposicional do Grupo Bauru (Cretáceo Superior): Comparação com os Sistemas de Leques Aluviais e Playa-Lakes da PréCordilheiraArgentina (Pleistoceno Superior-Atual)".Ao Departamento de Geologia e Recursos Naturais (DGRN) do Instituto de Geociências (IGe) da UNICAMP, pelo apoio na execução do projeto. Ao professor Juan Pablo Milana da Universidade de San Juan e à Maria Carolina Jesser Arraes pela valiosa ajuda nos trabalhos de campo.

\section{Referências}

Assine M.L. Leques Aluviais. In: Pedreira A.J., Aragão M.A.N.F., Magalhães A.J., Testa V. (eds.) Ambientes de sedimentação do Brasil (no prelo).

Batezelli A. 1998. Redefinição litoestratigráfica da unidade Araçatuba e da sua extensão regional na Bacia Bauru no Estado de São Paulo. Rio Claro, Dissertação de Mestrado, Instituto de Geociências e Ciências Exatas, Universidade Estadual Paulista. 110 p.

Batezelli A. 2003. Análise da sedimentação cretácea no Triângulo Mineiro e sua correlação com áreas adjacentes. Rio Claro, Tese de Doutoramento, Instituto de Geociências e Ciências Exatas, Universidade Estadual Paulista, $183 \mathrm{p}$.

Batezelli A., Saad, A. R., Etchebehere M.L. de C., Perinotto J.A. de J., Fulfaro V.J. 2003. Análise estratigráfica aplicada à Formação Araçatuba (Grupo Bauru - Ks) no centro-oeste do Estado de São Paulo. Geociências, 22: 333-352.

Batezelli A., Saad A. R., Perinotto J.A. de J., Fulfaro V.J. 2006. Análise estratigráfica aplicada à porção norte e nordeste da Bacia Bauru (Cretáceo Superior). Revista Brasileira de Geociências, 36(2):253-268.

Batezelli A., Saad A.R., Basilici G. 2007. Arquitetura deposicional e evolução da seqüência aluvial neocretácea da porção setentrional da Bacia Bauru, no sudeste brasileiro. Revista Brasileira de Geociências, 37(1):44-54.

Bridge J. S. 1993. Description and interpretation of fluvial deposits: a critical perspective. Sedimentology, 40(4):801810 .

Chrintz \& Clemmensen L.B. 1993. Draa reconstruction, the Permian Yellow Sands, northeast England. In: Pye K. \& Lancaster N. (eds.) Aeolian sediment. Spc. Plubls. Int. Ass. Sediment, vol. 16, p. 151-161.

Colombo F, Busquet P., Solé de Porta N., Heredia N., Rodríguez Fernández L.R., Limarino C.O. 2004. Depósitos lacustre holocenos en la valle del Río Jáchal (Pre-Cordillera Andina, San Juan, Argentina. Geo-Temas, 6(2):
47-50.

Cowan E.J. 1991. The Large-scale architecture of fluvial Westwater Canyon Member, Morrison Formation (Jurassic), San Juan Basin, New Mexico. In: Miall A.D. \& Tyler N. (eds.) The Three-Dimensional Facies Architecture of Terrigenous Clastics Sediments and Its Implications For Hydrocarbon Discovery and Recovery. Concepts in Sedimentology and Paleontology. Oklahoma, Tulsa, SEPM, v. 3, 309p.

Decelles P.G., Gray M.B., Ridgway K.D., Cole R.B., Pivnik D.A., Pequera N., Srivastava P. 1991. Controls on synorogenic alluvial-fan architecture, Beartooth Conglomerate (Paleocene), Wyoming and Montana. Sedimentology, 38(4):567-590.

Ferreira Jr. P. D. 1996. Modelo deposicional e evolução diagenética da Formação Uberaba, Cretáceo Superior da Bacia do Paraná, na região do Triângulo Mineiro. Dissertação de Mestrado, Universidade Federal de Ouro Preto, 175p.

Ferreira Jr., P. D. \& Guerra, W. J. 1995. Análise de elementos arquiteturais na caracterização do sistema fluvial da Formação Uberaba, Cretáceo Superior da Bacia do Paraná no Triângulo Mineiro. In: SBG/MG, Simpósio de Geologia de Minas Gerais, 8, Diamantina, anais, boletim, 13, p. 104-106.

Glennie K.W. 1970. Desert sedimentary environments. Amsterdam, Elsevier, Developments in Sedimentology, $\mathrm{n}^{\circ}$ 4.

Hasui Y. \& Haralyi N.L.E. 1991. Aspectos lito-estruturais e geofísicos do Soerguimento do Alto Paranaíba. Geociências, 10(1):67-77.

Hirst J.P.P. 1991. Variations in alluvial architecture across the Oligo-Mioceno Huesca Fluvial System Ebro Basin, Spain. In: Miall A.D. \& Tyler N. (eds.) The three-dimensional facies architecture of terrigenous clastics sediments and its implications for hydrocarbon discovery and recovery. Concepts in sedimentology and paleontol- 
ogy. SEPM, v. 3, Tulsa Oklahoma, USA, p. 111-121.

Hooke R.B. 1967. Processes on arid region alluvial fans. Journal of Geology, 75:438-460.

Hunter R.E. 1977. Terminology of cross stratified sedimentary layers and climbing ripples structures. Journal of Sedimentary Petrology, 47(2):697-706.

Jones S.J., Frostick L.E., Astin T.R. 2001. Braided stream and flood plain architecture: the Rio Vero Formation, Spanish Pyrenees. Sedimentary Geology, 139:229-260.

Junqueira-Brod T.C., Roig H.L., Gaspar J.C. Brod, J. A. \& Meneses, P. R. 2002. A Província Alcalina de Goiás e a extensão do seu vulcanismo kamafugítico. Revista Brasileira de Geociências, 32(4):559-566.

Komatsubara J. 2004. Fluvial architecture and sequence stratigraphy of the Eocene to Oligocene Iwaki Formation, northeast Japan: channel-fill related to sea-leval change. Sedimentary Geology, 168:109-123.

Lima C.C.U. de \& Villas-Boas G.S. 2000. A arquitetura deposicional da Formação Marizal (Cretáceo Inferior) na Bacia do Recôncavo, Bahia. Revista Brasileira de Geociências, 30(4):729-736.

Lowe D.R. 1979. Sedimentary gravity flows: their classification and some problems of application to natural flows and deposits. In: Doyle L.J. \& Pilkey O.H. (eds.) Geology of Continental Slope. Tulsa, SEPM, Special publication 27, p. 75-82.

Martinsen O. J., Ryseth A., Helland-Hansen W., Fleshe H., Torkildsen G., Idill S. 1999. Stratigraphic base level and fluvial architecture: Ericson Sandstone (Campanian), Rocky Springs Uplift, Sw Wyoming, USA. Sedimentology, 46:235-259.

McCarthy P.J. \& Plint A.J. 1998. Recognition of interfluvial sequence boundaries: integrating paleopedology and sequence stratigraphy. Geology, 26:387-390.

McCarthy P.J., Faccini U.F., Plint A.J. 1999. Evolution of an ancient floodplain: paleosols and alluvial architecture in a sequence stratigraphic framework, Cenomanian Dunvegan Formation, NE British Columbia, Canada. Sedimentology, 46:861-891.

Miall A.D. 1985. Architectural-element analysis: a new method of facies analysis applied to fluvial deposits. Earth Science Reviews, 22(4):261-300.

Miall A.D. 1988a. Reservoir heterogeneities in fluvial sandstones: lessons from outcrop studies. American Association of Petroleum Geologists Bulletin, 72(6):682-697.

Miall A.D. 1988b. Architectural elements and bounding surfaces in fluvial deposits: anatomy of the Kayenta Formation (Lower Jurassic) Southwest Colorado. Sedimentary Geology, 55(2):233-262.
Miall A.D. 1994. Reconstructing fluvial macroform architecture from two-dimensional outcrops: examples from the Castlegate Sandstone, Bookc Cliffs, Utah. Jounal of Sedimentary Research, B64(2): 146-158.

Miall A.D. 1996. The geology of fluvial deposits. Berlin, Springer-Verlag, 582p.

Miall A.D. \& Turner-Peterson C.E. 1989. Variations in fluvial style in the Westwater Canyon Member, Morrison Formation (Jurassic), San Juan Basin, Colorado Plateau. Sedimentary Geology, 63:21-60.

Miall A.D. \& Tyler N. 1991. The three-dimensional facies architecture of terrigenous clastics sediments and its implications for hydrocarbon discovery and recovery. Concepts in sedimentology and paleontology. Oklahoma, Tulsa, SEPM, v. 3, 309p.

Miall A.D. \& Jones B.G. 2003. Fluvial architecture of the Hawkesbury Sandstone (Triassic), near Sydney, Australia. Journal of Sedimentary Research, 73(4):531-545.

Nemec W. \& Steel R.J. 1984. Alluvial and coastal conglomerates: their significant features and some comments on gravelly mass-flow deposits. In: Koster E.H. \& Steel R.J. (eds.) Sedimentology of gravels and conglomerates. Calgary, Canadian Society of Petroleum Geologists, Memoir 10, p.1-31.

Nemec W., Porebski S. J., Steel R.J. 1980. Texture and structure of ressedimented conglomerates - examples from Ksiaz Formation (Famennian-Tournaisian), southwestern Poland. Sedimentology, 27:519-538.

Sawakuchi A.O. \& Giannini P.C. 2006. Complexidade em sistemas deposicionais. Rev. Bras. Geo., 36(2):347-358.

Smith S.A. 1990. The sedimentology and accretionary style of an ancient gravel-bed stream: the Budleigh Salterton Pebble Beds (Lower Triassic), Southwest England. Sedimentary Geology, 67:199-219.

Stanistreet I.G. \& McCarthy T.S. 1993. The Okavango Fan and the classification of sub aerial fan systems. Sedimentary Geology, 85:115-133.

Simons D.B., Richardson E.V., Nordin C.F. 1965. Sedimentary structures generated by flow in alluvial channels. SEPM Special Publication, 12:34-52.

Steel J.R. 1974. New Red Sandstone floodplain and piedmont sedimentation in the Hebridean province, Scotland. Journal of Sedimentary Petrology, 44:336-357.

Wasson R.J. 1979. Sedimentation history of the Mundi-Mundi alluvial fans, western New South Wales. Sedimentary Geology, 22:21-51.

Manuscrito AE 097-2006

Submetido em 19 de setembro de 2007 Aceito em 20 de dezembro de 2007 